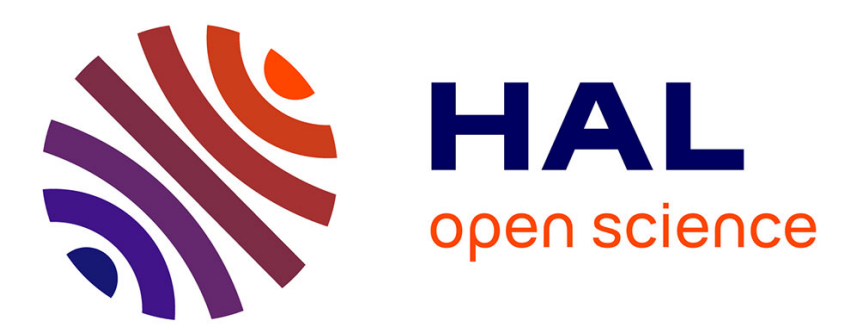

\title{
Photoinduced water oxidation in pyrimidine-water clusters: A combined experimental and theoretical study
} Xiang Huang, Juan Abrate, Johannes Ehrmaier, Jennifer Anna Noble, Weiwei Xie, Andrzej Sobolewski, Claude Dedonder-Lardeux, Christophe Jouvet, Wolfgang Domcke

\section{To cite this version:}

Xiang Huang, Juan Abrate, Johannes Ehrmaier, Jennifer Anna Noble, Weiwei Xie, et al.. Photoinduced water oxidation in pyrimidine-water clusters: A combined experimental and theoretical study. Physical Chemistry Chemical Physics, 2020, 22, pp.12502-12514. 10.1039/D0CP01562H . hal-02566448

\section{HAL Id: hal-02566448 \\ https://hal.science/hal-02566448}

Submitted on 6 Nov 2020

HAL is a multi-disciplinary open access archive for the deposit and dissemination of scientific research documents, whether they are published or not. The documents may come from teaching and research institutions in France or abroad, or from public or private research centers.
L'archive ouverte pluridisciplinaire HAL, est destinée au dépôt et à la diffusion de documents scientifiques de niveau recherche, publiés ou non, émanant des établissements d'enseignement et de recherche français ou étrangers, des laboratoires publics ou privés. 


\title{
Photoinduced water oxidation in pyrimidine-water clusters: A combined experimental and theoretical study
}

\author{
Xiang Huang ${ }^{1}$, Juan-Pablo Aranguren ${ }^{2,3,4}$, Johannes Ehrmaier ${ }^{1}$, Jennifer A. Noble ${ }^{4}$, \\ Weiwei Xie ${ }^{5}$, Andrzej L. Sobolewski ${ }^{6}$, Claude Dedonder-Lardeux ${ }^{4}$, \\ Christophe Jouvet ${ }^{4}$ and Wolfgang Domcke ${ }^{1}$
}

\footnotetext{
${ }^{1}$ Department of Chemistry, Technical University of Munich, Garching, Germany

${ }^{2}$ CNRS, Aix Marseille Université, Laboratoire Physique des Interactions Ioniques et Moléculaires, Marseille, France

${ }^{3}$ Departamento de Fisicoquímica, Facultad de Ciencias Químicas, Universidad Nacional de Córdoba, Haya de la Torre y Medina Allende, Ciudad Universitaria, X5000HUA Córdoba, Argentina

${ }^{4}$ Centro Láser de Ciencias Moleculares, Universidad Nacional de Córdoba, Haya de la Torre s/n, Pabellón Argentina, Ciudad Universitaria, X5000HUA Córdoba, Argentina

${ }^{5}$ Institute of Physical Chemistry, Karlsruhe Institute of Technology, Karlsruhe, Germany

${ }^{6}$ Institute of Physics, Polish Academy of Sciences, Warsaw, Poland
} 


\section{Abstract}

The photocatalytic oxidation of water with molecular or polymeric N-heterocyclic chromophores is a topic of high current interest in the context of artificial photosynthesis, that is, the conversion of solar energy to clean fuels. Hydrogen-bonded clusters of N-heterocycles with water molecules in a molecular beam are simple model systems for which the basic mechanisms of photochemical water oxidation can be studied under well-defined conditions. In this work, we explored the photoinduced $\mathrm{H}$-atom transfer reaction in pyrimidine-water clusters yielding pyrimidinyl and hydroxyl radicals with laser spectroscopy, mass spectrometry and trajectory-based ab initio molecular dynamics simulations. The oxidation of water by photoexcited pyrimidine is unequivocally confirmed by the detection of the pyrimidinyl radical. The dynamics simulations provide information on the time scales and branching ratios of the reaction. While relaxation to local minima of the $S_{1}$ potential-energy surface is the dominant reaction channel, the $\mathrm{H}$-atom transfer reaction occurs on ultrafast time scales (faster than about $100 \mathrm{fs}$ ) with a branching ratio of a few percent. From the relaxed population in the $\mathrm{S}_{1}$ state, $\mathrm{H}$ atom transfer yielding pyrimidinyl and hydroxyl radicals can occur on much longer time scales (picoseconds to nanoseconds) by $\mathrm{H}$-atom tunneling.

\section{Introduction}

Nitrogen-rich aromatic heterocycles, such as s-triazine or heptazine (tri-s-triazine, Hz), recently became of great interest as building blocks of polymeric materials or covalent organic frameworks which exhibit promising catalytic activity for the evolution of molecular hydrogen from protic solvents (amines, alcohols or water) under irradiation with near UV light. ${ }^{1-5}$ While the synthesis of so-called graphitic carbon nitrides ${ }^{6}$ by pyrolysis of simple precursor molecules is straightforward, neither the chemical composition nor the molecular structure of these materials are precisely defined. Despite extensive research efforts in the past ten years, the photophysical and photochemical processes underlying the photocatalytic hydrogen evolution reaction with graphitic carbon nitride materials remain a mystery. ${ }^{7,8}$

To gain insight into the fundamental photophysics of heptazine-based materials, a heptazine-derived molecular photocatalyst, tri-anisole-heptazine (TAHz), was recently synthesized by Schlenker and coworkers. ${ }^{9}$ It was shown that photoexcited TAHz can oxidize water via an $\mathrm{H}$-atom transfer reaction, resulting in the quenching of the excited state of $\mathrm{TAHz}$ and the liberation of $\mathrm{OH}$ radicals that were detected using terephthalic acid. ${ }^{9}$ These findings provide evidence that photooxidation of water with 
heptazine does not inherently require transport of charge carriers in polymeric or crystalline materials, but rather may occur as a molecular photochemical reaction in homogeneous solution. Since TAHz is still of formidable size for accurate ab initio simulations of the photochemical dynamics, it is of interest to search for even simpler chromophores which can reveal at least some of the mechanisms which are fundamental for the light-driven water oxidation reaction.

The photoinduced oxidation of water by a molecular chromophore was first demonstrated for pyridine-water $\left(\mathrm{Py}-\left(\mathrm{H}_{2} \mathrm{O}\right)_{n}\right)$ clusters in a molecular beam experiment by Jouvet and coworkers, ${ }^{10}$ confirming the predictions of earlier computational studies. ${ }^{11-13}$ The pyridine (Py) chromophore in pyridine-water $\left(\mathrm{Py}-\left(\mathrm{H}_{2} \mathrm{O}\right)_{n}\right)$ clusters was excited to the lowest bright state $\left({ }^{1} \pi \pi^{*}, \approx 4.8 \mathrm{eV}(260 \mathrm{~nm})\right)$. The light-induced abstraction of a hydrogen atom from the water cluster was observed by the detection of the pyridinyl $\left(\mathrm{PyH}^{\bullet}\right)$ radical in a mass spectrometer after ionization by a probe laser. ${ }^{10}$ The excitation energy of Py is $1.8 \mathrm{eV}$ lower than the energy necessary for the direct photodissociation of the $\mathrm{OH}$ bond of water molecules $(6.66 \mathrm{eV}, 186 \mathrm{~nm})$. While the excitation energy of Py is well outside the range of the solar spectrum on the surface of Earth, this experiment demonstrated the fundamental principle that molecular chromophores can drive the dissociation of water molecules well below the intrinsic photodissociation threshold of water. It also was shown in this work that the excess hydrogen atom of the PyH ${ }^{\bullet}$ radical can be photodetached by $255 \mathrm{~nm}$ light. This photodetachment reaction recovers the Py molecule and thus closes the photocatalytic cycle. ${ }^{10}$

Photochemical reactions in the well-defined environment of cold molecular clusters were investigated in the past for a variety of chromophores and solvent molecules. These studies provided important insights into the detailed mechanisms of photochemical reactions, such as proton transfer through molecular wires, ${ }^{14-17}$ hydrogen transfer to solvents in chromophore-solvent clusters, ${ }^{18-24}$ solvent isomerization, ${ }^{25-27}$ characterization of transition states of reactions ${ }^{28-30}$ or chiral discrimination. ${ }^{31}$ One of the advantages of investigations of the photochemistry of small chromophores in small, size-selected clusters is the possibility of comparison of experimental data with the results of theory which can be performed at a significantly higher level than is possible in the investigation of condensed-phase reactions. 
In the present work, we extended this approach to the photochemistry of pyrimidine-water (Pm$\left.\left(\mathrm{H}_{2} \mathrm{O}\right)_{n}\right)$ clusters as a first step towards studies of the photochemistry of nitrogen-rich chromophores in water clusters. The controlled extension of the complexity of photochemical systems from single chromophores in small solvent clusters via single chromophores in room-temperature liquid solution towards multi-chromophoric systems in solution is envisioned as a long-term strategy towards the development of a complete understanding of the mechanisms involved in the conversion of solar light to clean fuels in artificial photosynthetic devices.

\section{Experimental methods}

The setup that we used in this work is composed of a pulsed supersonic expansion combined with a time of flight (TOF) mass spectrometer. In the first experiment, a discharge source, the same as that used in previous experiments to produce either cold neutral van der Waals species ${ }^{32}$ or protonated molecular ions,${ }^{33}$ is used to produce hydrogenated radicals. It consists of a pulsed high-voltage discharge located a few $\mathrm{mm}$ after the pulsed nozzle which produces pyrimidinyl radicals (hereafter $\mathrm{PmH} \mathrm{H}^{\bullet}$ ) from a gas mixture of $\mathrm{He} / \mathrm{H}_{2} /$ pyrimidine. The radicals are cooled down in the expansion and ionized between the extraction plates of the reflectron TOF mass spectrometer (Jordan TOF Products, Inc).

In the second experiment, the discharge is removed and $\mathrm{Pm}-\left(\mathrm{H}_{2} \mathrm{O}\right)_{n}$ clusters are produced by expanding a mixture of water and $\mathrm{Pm}$ at their respective vapor pressures at $60^{\circ} \mathrm{C}$ with $\mathrm{He}$ (between 2 and 6 bar). Two laser beams are temporally and spatially synchronized between the extraction plates of the mass spectrometer. The pump laser excites the clusters while the probe laser ionizes the PmH• radicals.

The lasers used are YAG-pumped nanosecond OPO lasers (EXSPLA model-NT342B), which have a $10 \mathrm{~Hz}$ repetition rate, a resolution (FWHM) of $8 \mathrm{~cm}^{-1}$ and a minimum scanning step of $0.02 \mathrm{~nm}$. The lasers are focused in the middle of the extraction zone of the TOF mass spectrometer. These lasers can be scanned from the visible to the UV in three regions: from 410 to $709 \mathrm{~nm}$ (OPO signal), from 296 to $409.9 \mathrm{~nm}$ (frequency mixing) and from 225 to $295.9 \mathrm{~nm}$ (frequency doubling). 


\section{Computational Methods}

The equilibrium geometries of $\mathrm{Pm}$ and $\mathrm{Pm}-\mathrm{H}_{2} \mathrm{O}$ complexes were determined by minimizing the energy of the electronic ground-state using second-order Møller-Plesset (MP2) perturbation theory ${ }^{34}$. The geometries were optimized without symmetry constraints.

The second-order algebraic-diagrammatic-construction $(\mathrm{ADC}(2))$ method $^{35-37}$ was used to calculate vertical excitation energies, oscillator strengths and dipole moments of excited states. The accuracy of the $\mathrm{ADC}(2)$ method for the calculation of excitation energies and excited-state potential-energy (PE) surfaces of clusters of heteroaromatic systems with water molecules was critically evaluated in earlier studies in comparison with CASSCF/CASPT2 and equation-of-motion coupled-cluster (EOM-CC) calculations. ${ }^{12,38} \mathrm{ADC}(2)$ has thereby been established as a reliable tool to describe excited-state H-atom transfer reactions in complexes of $\mathrm{N}$-heterocycles with water molecules.

The driving coordinate for the construction of the minimum-energy reaction path (relaxed scan) for the $\mathrm{H}$-atom transfer reaction from water to $\mathrm{Pm}$ is chosen as the $\mathrm{OH}$ bond length $R_{\mathrm{OH}}$ of the water molecule which is hydrogen-bonded to the $\mathrm{N}$-atom of Pm. For one-dimensional relaxed scans, $R_{\mathrm{OH}}$ was fixed, while the energy of a given electronic state was minimized with respect to all other nuclear degrees of freedom. For technical reasons, $\mathrm{C}_{\mathrm{s}}$ symmetry (coplanar $\mathrm{Pm}$ and $\mathrm{H}_{2} \mathrm{O}$ moieties) had to be enforced to allow the minimization of the energies of the lowest excited states of $\mathrm{A}^{\prime}$ or $\mathrm{A}^{\prime \prime}$ symmetry. The energies of the other electronic states were determined by single-point energy calculations at these optimized geometries.

Relaxed two-dimensional PE surfaces were computed in analogous manner by fixing $R_{\mathrm{OH}}$ as well as the distance $R_{\mathrm{ON}}$ between the donor O-atom of water and the acceptor $\mathrm{N}$-atom of $\mathrm{Pm}$. All other nuclear degrees of freedom were relaxed to minimize the energy of the lowest excited states of either $\mathrm{A}^{\prime}$ or $\mathrm{A}^{\prime \prime}$ symmetry. 
Dunning's correlation-consistent double- $\zeta$ basis set (cc-pVDZ) ${ }^{39}$ was employed for the electronicstructure calculations. The electronic-structure calculations were performed with the TURBOMOLE program package ${ }^{40}$ using the resolution-of-the-identity (RI) approximation. ${ }^{41}$

The absorption spectra of the $\mathrm{Pm}-\mathrm{H}_{2} \mathrm{O}$ and $\mathrm{Pm}-\left(\mathrm{H}_{2} \mathrm{O}\right)_{4}$ clusters were simulated using a protocol which was proposed, among others, by Heller and coworkers and Barbatti and coworkers. ${ }^{42,}{ }^{43}$ A set of 2000 geometries was sampled from the harmonic-oscillator thermal Wigner distribution at room temperature. The lowest five vertical excitation energies and the corresponding oscillator strengths were computed for this ensemble. The line spectra generated by this ensemble were convoluted with a Lorentzian of $0.05 \mathrm{eV}$ full width at half maximum to generate a smooth absorption profile.

The dynamics of the photoinduced $\mathrm{H}$-atom transfer reaction from water to $\mathrm{Pm}$ in the $\mathrm{Pm}-\mathrm{H}_{2} \mathrm{O}$ and $\mathrm{Pm}-\left(\mathrm{H}_{2} \mathrm{O}\right)_{4}$ complexes was studied by ab initio on-the-fly trajectory surface-hopping ( $\left.\mathrm{SH}\right)$ simulations with the ADC(2) method. We employed a recently developed Landau-Zener (LZ) surface-hopping algorithm. ${ }^{4-47}$ This algorithm is a computationally efficient and accurate alternative to the widely used fewest-switches surface-hopping (FSSH) method of Tully. ${ }^{48}$ In the LZ-based surface-hopping (LZSH) algorithm, the transition probability between electronic states is determined directly from the topography of the adiabatic potentials in energy-crossing regions, avoiding the computation of rapidly varying derivative couplings near avoided crossings and conical intersections (CIs). The results of simulations with the LZSH method have been compared with those of simulations with the FSSH method and with the results of exact quantum dynamics calculations in several studies of few-state few-mode model systems. ${ }^{45-47}$

In the present work, we used an implementation of the LZSH method based on MP2 and ADC(2) energies and gradients computed with the TURBOMOLE program package. ${ }^{47}$ Similar ab initio on-thefly LZ-based trajectory SH simulations of the photochemical dynamics of molecular systems were recently performed by Zhu and coworkers ${ }^{49}$ and Kono and coworkers ${ }^{50}$. The initial conditions for the dynamics simulations were selected from the thermal Wigner sample which was generated for the calculation of the absorption spectra. From this ensemble, positions and moments were selected which have excited-state energies within a band of $0.1 \mathrm{eV}$ around the maximum of the absorption spectrum. 
This sampling, which mimics excitation with a narrow-band laser near the maximum of the absorption spectrum, as is done in the present experiment, results in 207 and 224 excited-state trajectories, respectively, for the $\mathrm{Pm}-\mathrm{H}_{2} \mathrm{O}$ and $\mathrm{Pm}-\left(\mathrm{H}_{2} \mathrm{O}\right)_{4}$ complexes. The trajectories were initiated in the adiabatic $\mathrm{S}_{3}$ state (the bright ${ }^{1} \pi \pi^{*}$ state of $\mathrm{Pm}$ ) and propagated up to $500 \mathrm{fs}$ with a time step of $0.5 \mathrm{fs}$. When the energy gap between the current adiabatic state and the $\mathrm{S}_{0}$ state decreased below $0.2 \mathrm{eV}$, the trajectory was terminated. This event was counted as nonradiative transition to the $\mathrm{S}_{0}$ state. An instantaneous $\mathrm{H}-$ atom transfer from water to $\mathrm{Pm}$ is counted when the distance of the active $\mathrm{H}$-atom to the acceptor Natom of Pm decreases below 1.3 $\AA$. A trajectory is counted as reactive at the end of the time window (500 fs) when the cluster contains $\mathrm{PmH}^{\bullet}$ and $\mathrm{OH}^{\bullet}$ radicals, either as hydrogen-bonded biradicals or as separated radicals in the water cluster.

\section{Results}

\subsection{Structures and absorption spectra}

We selected the $\mathrm{Pm}-\mathrm{H}_{2} \mathrm{O}$ and $\mathrm{Pm}-\left(\mathrm{H}_{2} \mathrm{O}\right)_{4}$ complexes as representative examples of $\mathrm{Pm}-\left(\mathrm{H}_{2} \mathrm{O}\right)_{n}$ complexes. For the $\mathrm{Pm}-\mathrm{H}_{2} \mathrm{O}$ cluster, a detailed computational investigation of excited-state reaction paths and PE profiles is possible, see below. The Pm- $\left(\mathrm{H}_{2} \mathrm{O}\right)_{4}$ cluster, on the other hand, is expected to have a sufficient number of internal degrees of freedom to allow dissipation of the excess energy generated by the $\mathrm{H}$-atom transfer reaction in the cluster. Ab initio simulations for significantly larger clusters are beyond the limit of our computational resources.

The calculated equilibrium geometries of the $\mathrm{Pm}-\mathrm{H}_{2} \mathrm{O}$ and $\mathrm{Pm}-\left(\mathrm{H}_{2} \mathrm{O}\right)_{4}$ complexes are shown in Figures 1(a) and 1(b), respectively. For the $\mathrm{Pm}-\mathrm{H}_{2} \mathrm{O}$ complex, the conformer with the in-plane orientation of the water molecule is less stable by $0.07 \mathrm{eV}$ than the conformer with perpendicular orientation of the water molecule. This tiny energy difference is irrelevant for the purposes of the present investigation and we therefore restricted the exploration of the excited-state PE surfaces to the in-plane conformer of $\mathrm{Pm}-\mathrm{H}_{2} \mathrm{O}$. For the $\mathrm{Pm}-\left(\mathrm{H}_{2} \mathrm{O}\right)_{4}$ complex, numerous equilibrium structures with similar energies exist. We selected a structure in which the $\left(\mathrm{H}_{2} \mathrm{O}\right)_{4}$ cluster is bonded as $\mathrm{H}$-atom donor to one of 
the $\mathrm{N}$-atoms of Pm. A weak $\mathrm{CH} \cdots \mathrm{O}$ hydrogen bond gives this cluster additional stability, see Fig 1(b). The hydrogen bond length between the accepting $\mathrm{N}$-atom of Pm and the H-atom of the water molecule decreases from $2.023 \AA$ for $\mathrm{Pm}-\mathrm{H}_{2} \mathrm{O}$ to $1.811 \AA$ for $\mathrm{Pm}-\left(\mathrm{H}_{2} \mathrm{O}\right)_{4}$, indicating a considerable strengthening of the hydrogen bond with Pm in the larger cluster. The $\left(\mathrm{H}_{2} \mathrm{O}\right)_{4}$ cluster of Fig. 1(b) is of the so-called double-donor double-acceptor type. Compared with cyclic $\left(\mathrm{H}_{2} \mathrm{O}\right)_{4}$ clusters, this cluster exhibits a stronger hydrogen bond with $\mathrm{Pm}$. Moreover, the double-acceptor property of the $\mathrm{H}_{2} \mathrm{O}$ molecule which is hydrogen-bonded to Pm softens the $\mathrm{OH}$ bond involved in hydrogen bonding with the $\mathrm{N}$-atom of Pm. Both features are favourable for the $\mathrm{H}$-atom transfer reaction.

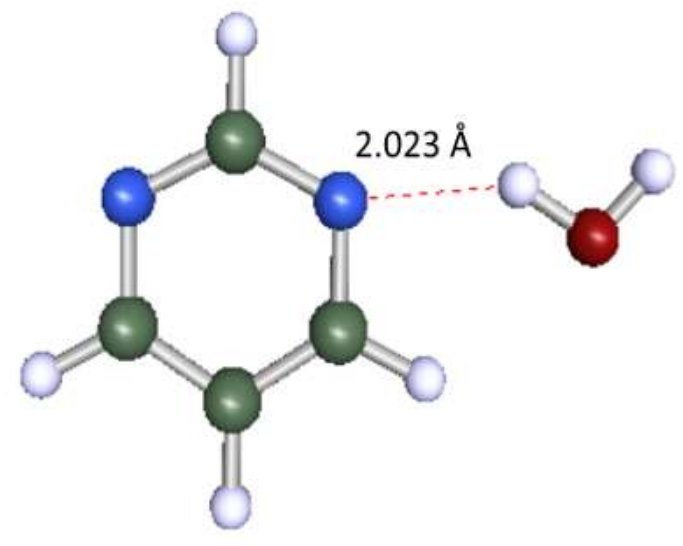

a)

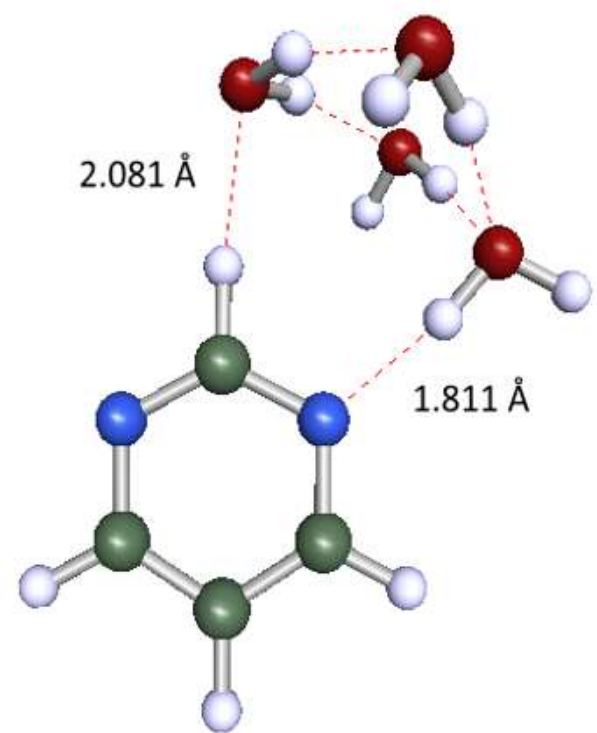

b)

Figure 1. Ground-state equilibrium geometries of the $\mathrm{Pm}-\mathrm{H}_{2} \mathrm{O}(\mathrm{a})$ and $\mathrm{Pm}-\left(\mathrm{H}_{2} \mathrm{O}\right)_{4}$ (b) complexes.

The vertical excitation energies of the lowest singlet excited states of isolated $\mathrm{Pm}$, the $\mathrm{Pm}-\mathrm{H}_{2} \mathrm{O}$ complex and the Pm- $\left(\mathrm{H}_{2} \mathrm{O}\right)_{4}$ complex are listed in Table 1, including their dominant orbital configurations, oscillator strengths (in parentheses) and dipole moments (in brackets). The HF molecular orbitals (MOs) of $\mathrm{Pm}$ and $\mathrm{Pm}-\left(\mathrm{H}_{2} \mathrm{O}\right)_{4}$, which are primarily involved in the electronic configurations of the lowest five excited states, are displayed in Fig 2. The highest occupied molecular orbital (HOMO) of Pm is a $\pi$ orbital and the lowest unoccupied molecular orbital (LUMO) of Pm is a $\pi^{*}$ orbital. It should 
be noted that the n orbitals (HOMO-1 and HOMO-3 in Pm) are partly delocalized over p orbitals of the water molecules in the Pm- $\left(\mathrm{H}_{2} \mathrm{O}\right)_{4}$ complex (see Fig 2), which indicates a partially covalent character of the water-Pm hydrogen bond in this cluster. The $S_{1}$ and $S_{2}$ excited states of Pm are of $n \pi^{*}$ character and are dark in absorption. The lowest bright excited state is the $S_{3}$ state of $\pi \pi^{*}$ character with an excitation energy of $5.53 \mathrm{eV}$ in isolated $\mathrm{Pm}$. Unexpectedly, the excitation energies of the $\mathrm{n} \pi^{*}$ excited states of Pm$\mathrm{H}_{2} \mathrm{O}$ and $\mathrm{Pm}-\left(\mathrm{H}_{2} \mathrm{O}\right)_{4}$ are negligibly affected by the hydrogen bonding with water molecules. Usually, for example for pyridine (Py) in aqueous environments, ${ }^{51}$ it is found that hydrogen-bonding with water molecules stabilizes the $\mathrm{n}$ orbitals more effectively than $\pi$ and $\pi^{*}$ orbitals, which results in an increase of the excitation energies of $n \pi^{*}$ states. This effect is not observed in Pm-water clusters. To explain this observation, the variation of the orbital energies of $\mathrm{Pm}$ with increasing complexation with water is displayed in Fig S1 of the Supplementary Information. This figure shows that the $n, \pi$ and $\pi^{*}$ orbitals are stabilized by approximately the same amount with increasing number of water molecules. While solvation effects on the orbital energies are substantial, they cancel approximately for the excitation energies (orbital energy differences) of Pm-water complexes.

Table 1. Vertical excitation energies (in eV) of the lowest five singlet excited states and the lowest $C T$ state of $\mathrm{Pm}$, the $\mathrm{Pm}-\mathrm{H}_{2} \mathrm{O}$ complex and the $\mathrm{Pm}-\left(\mathrm{H}_{2} \mathrm{O}\right)_{4}$ complex, calculated at the $\mathrm{ADC}(2)$ level. Oscillator strengths are given in parentheses, dipole moments (in Debye) in brackets.

\begin{tabular}{|c|c|c|c|c|c|c|}
\hline \multirow{2}{*}{$\begin{array}{l}\text { State } \\
\mathrm{S}_{1}\left(\mathrm{n} \pi^{*}\right)\end{array}$} & \multicolumn{3}{|c|}{ Transition Orbitals } & \multirow{2}{*}{$\begin{array}{l}\mathrm{Pm} \\
4.49(0.005)[0.7]\end{array}$} & \multirow{2}{*}{$\begin{array}{l}\mathrm{Pm}-\mathrm{H}_{2} \mathrm{O} \\
4.59(0.005)[2.7]\end{array}$} & \multirow{2}{*}{$\begin{array}{l}\mathrm{Pm}-\left(\mathrm{H}_{2} \mathrm{O}\right)_{4} \\
4.47(0.003)[5.8]\end{array}$} \\
\hline & HOMO-1 & $\rightarrow$ & LUMO & & & \\
\hline $\mathrm{S}_{2}\left(\mathrm{n} \pi^{*}\right)$ & HOMO-1 & $\rightarrow$ & LUMO+1 & $4.80(0.000)[0.8]$ & $4.91(0.000)[1.5]$ & $4.88(0.001)[7.2]$ \\
\hline $\mathrm{S}_{3}\left(\pi \pi^{*}\right)$ & HOMO & $\rightarrow$ & LUMO & $5.53(0.023)[2.3]$ & $5.53(0.025)[0.7]$ & $5.50(0.032)[9.1]$ \\
\hline $\mathrm{S}_{4}\left(\mathrm{n} \pi^{*}\right)$ & HOMO-3 & $\rightarrow$ & LUMO & $6.08(0.000)[0.8]$ & $6.17(0.000)[2.6]$ & $6.10(0.000)[5.8]$ \\
\hline $\mathrm{S}_{5}\left(\mathrm{n} \pi^{*}\right)$ & HOMO-3 & $\rightarrow$ & LUMO+1 & $6.32(0.006)[0.5]$ & $6.42(0.006)[1.1]$ & $6.41(0.004)[6.6]$ \\
\hline CT & $\mathrm{p}\left(\mathrm{H}_{2} \mathrm{O}\right)$ & $\rightarrow$ & LUMO & --- & $8.16(0.028)[16.2]$ & $8.89(0.000)[14.9]$ \\
\hline
\end{tabular}




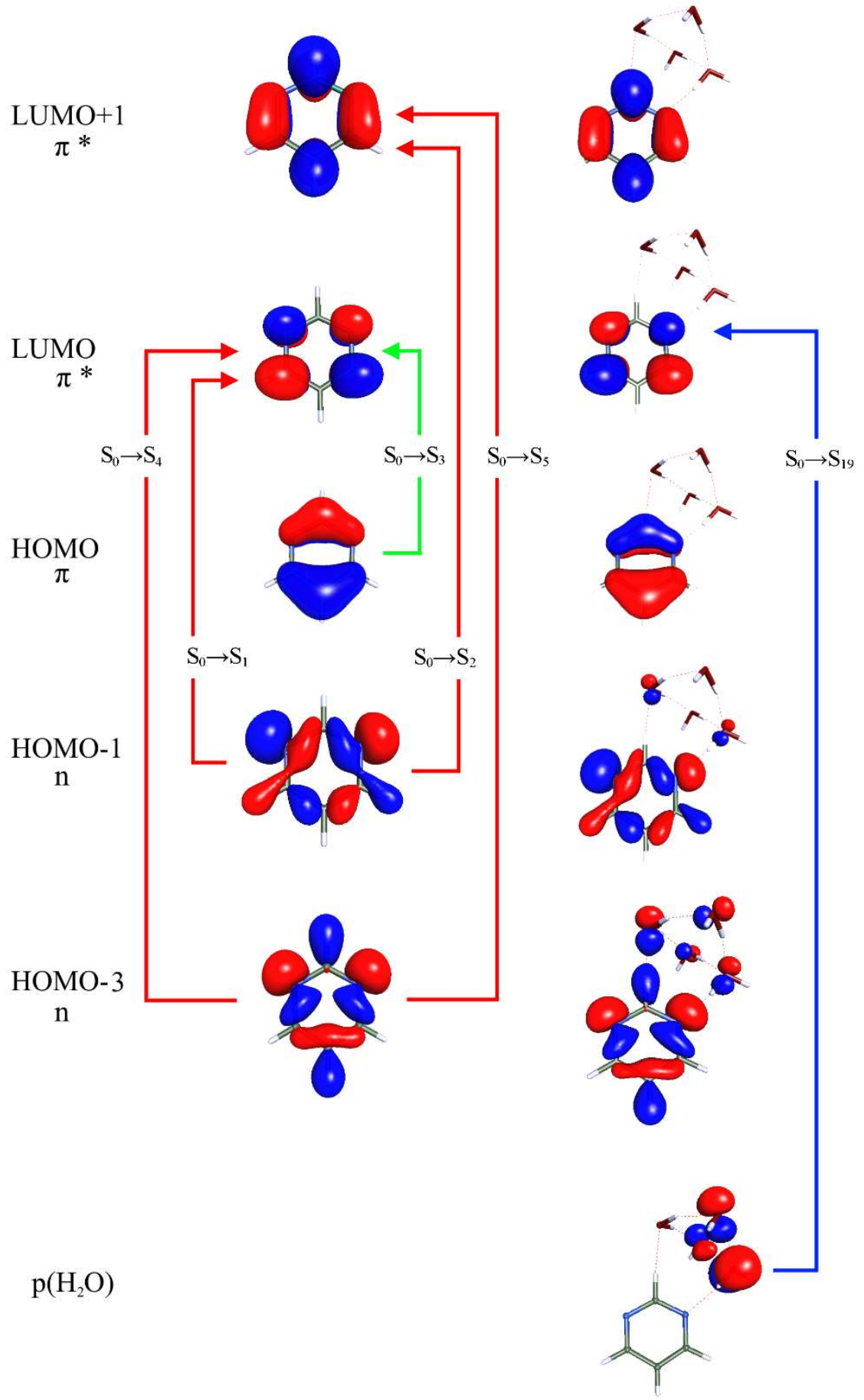

Figure 2. Hartree-Fock molecular orbitals of Pm (left) and of the Pm- $\left(\mathrm{H}_{2} \mathrm{O}\right)_{4}$ complex (right) involved in the configurations of the lowest five singlet excited states and the charge-transfer state. $n \pi^{*}$ transitions are marked in red, $\pi \pi^{*}$ transitions are marked in green. $p\left(\mathrm{H}_{2} \mathrm{O}\right)$ denotes an orbital which is mostly localized on the oxygen atom of the water molecule adjacent to Pm. Excitation from this orbital to the LUMO of Pm results in the charge-transfer state (transition marked in blue). Note that the $n$ orbitals (HOMO-3, HOMO-1) of the Pm- $\left(\mathrm{H}_{2} \mathrm{O}\right)_{4}$ complex are partially delocalized over the water 
molecules, showing that the hydrogen bond has partially covalent character. The $\pi$ and $\pi^{*}$ orbitals, on the other hand, are exclusively localized on Pm.

The $\mathrm{S}_{9}$ state in the $\mathrm{Pm}-\mathrm{H}_{2} \mathrm{O}$ complex and the $\mathrm{S}_{19}$ state in the $\mathrm{Pm}-\left(\mathrm{H}_{2} \mathrm{O}\right)_{4}$ complex are water-to-Pm charge-transfer (CT) states. They correspond to the excitation of an electron from a p orbital of the hydrogen-bonded water molecule to the LUMO of Pm, as indicated by the blue arrow in Fig 2 for the Pm- $\left(\mathrm{H}_{2} \mathrm{O}\right)_{4}$ cluster. The CT character of these states is confirmed by the exceptionally large dipole moment of about 15 Debye, see Table 1. The excitation energies of these CT state are higher than 8.0 $\mathrm{eV}$ at the ground-state equilibrium geometry. Since the $\mathrm{p}$ orbital of water is more strongly stabilized in the larger water cluster, the excitation energy of the CT state is about $0.7 \mathrm{eV}$ higher in $\mathrm{Pm}-\left(\mathrm{H}_{2} \mathrm{O}\right)_{4}$ than in $\mathrm{Pm}-\mathrm{H}_{2} \mathrm{O}$. For Pm- $\left(\mathrm{H}_{2} \mathrm{O}\right)_{4}$, two additional transitions of CT character, $\mathrm{S}_{7}$ and $\mathrm{S}_{8}$, were found (not listed in Table 1). These CT states correspond to transitions of an electron from the p orbital of the water molecule which is weakly hydrogen-bonded with the $\mathrm{CH}$ group of the chromophore (see Fig 1(b)) to $\pi^{*}$ orbitals of Pm. In these CT states, the water molecule adjacent to Pm is oxidized by hole transfer from $\mathrm{Pm}$ to $\mathrm{H}_{2} \mathrm{O}$. In contrast to the $\mathrm{CT}$ state involving the water molecule $\mathrm{H}$-bonded to the $\mathrm{N}$-atom of $\mathrm{Pm}$, the driving force for proton transfer is weak in the $\mathrm{CT}$ states involving the $\mathrm{CH}$ group, since the protons are firmly $\mathrm{H}$-bonded in the water cluster and the $\mathrm{H}$-atom transfer requires an energetically unfavorable rehybridization of the aromatic ring. It is likely that these additional CT states are rapidly deactivated by internal conversion to lower electronic states prior to proton transfer. In the dynamics simulations (see below) we did not find evidence for any $\mathrm{H}$-atom transfer event from the $\left(\mathrm{H}_{2} \mathrm{O}\right)_{4}$ cluster to the $\mathrm{CH}$ group of Pm.

The simulated absorption spectra of the $\mathrm{Pm}-\mathrm{H}_{2} \mathrm{O}$ and $\mathrm{Pm}-\left(\mathrm{H}_{2} \mathrm{O}\right)_{4}$ complexes are shown in Fig 3 in comparison with the experimental excitation/ionization spectrum recorded in this work for a distribution of Pm- $\left(\mathrm{H}_{2} \mathrm{O}\right)_{n}$ clusters. The band maximum of the $\mathrm{Pm}-\mathrm{H}_{2} \mathrm{O}$ complex is predicted by the ADC(2) calculations at $5.42 \mathrm{eV}$, which is $0.11 \mathrm{eV}$ red-shifted from the vertical $\mathrm{S}_{3}$ excitation energy. For the Pm$\left(\mathrm{H}_{2} \mathrm{O}\right)_{4}$ complex, the band maximum is predicted at $5.38 \mathrm{eV}$, which is $0.12 \mathrm{eV}$ red-shifted from the vertical excitation energy of the $S_{3}\left(\pi \pi^{*}\right)$ state. From the calculations, it seems that the maximum of the absorption profile does not depend significantly on the cluster size. The maximum of the experimental 
spectrum is at $5.35 \pm 0.05 \mathrm{eV}$. The excellent agreement between simulations and experiments confirms the high accuracy of the $\mathrm{ADC}(2)$ method for calculating excitation energies in the Franck-Condon region.

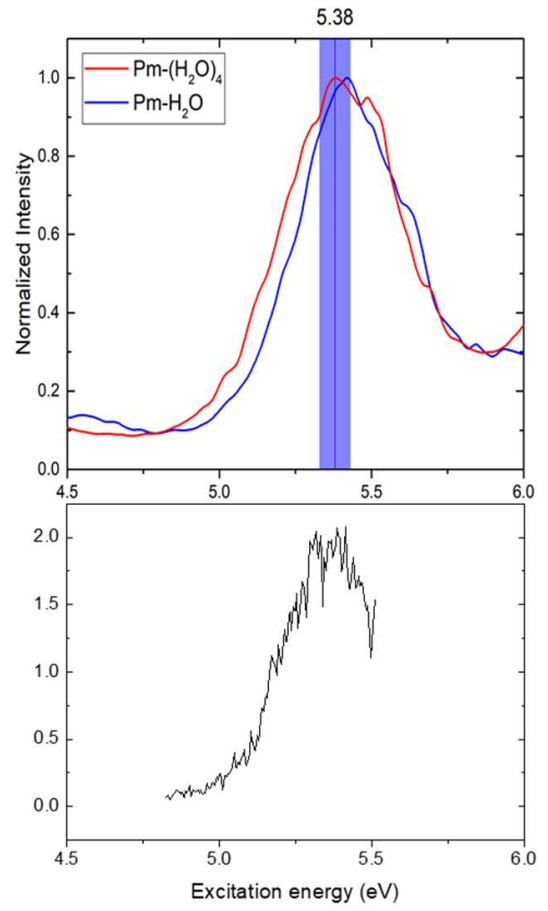

Figure 3. Upper panel: Absorption spectra of the $\mathrm{Pm}-\mathrm{H}_{2} \mathrm{O}$ and $\mathrm{Pm}-\left(\mathrm{H}_{2} \mathrm{O}\right)_{4}$ clusters computed with the nuclear ensemble model and the ADC(2) electronic-structure method. The initial conditions for the dynamics simulations were sampled from the energy window shaded in blue $(5.38 \pm 0.05 \mathrm{eV})$. Lower panel: Experimental excitation/ionization spectrum of Pm- $\left(\mathrm{H}_{2} \mathrm{O}\right)_{n}$ clusters obtained by two-photon ionization and recorded at the $\mathrm{Pm}-\left(\mathrm{H}_{2} \mathrm{O}\right)^{+}{ }_{n=1}$ mass. The signal presumably contains contributions from larger clusters which have evaporated water molecules after ionization.

\subsection{Detection and spectroscopic characterization of the $\mathrm{PmH} \cdot$ radical}

Fig 4 shows mass spectra obtained in experiments with the probe (ionization) laser set to $353.8 \mathrm{~nm}$ and with the discharge on (black trace) or off (red trace). In the absence of the discharge, no ion signal is observed, since pyrimidine $(\mathrm{m} / \mathrm{z}=80)$ does not absorb at this wavelength (Fig SI.3 in the supporting information shows the REMPI spectrum of pyrimidine). When the discharge is on, an intense peak at 
$m / z=81$ with its isotopic companion at $m / z=82$ is obtained, indicating that protonated pyrimidine $\mathrm{PmH}^{+}$ is observed via ionization of the $\mathrm{PmH} \cdot$ radical.

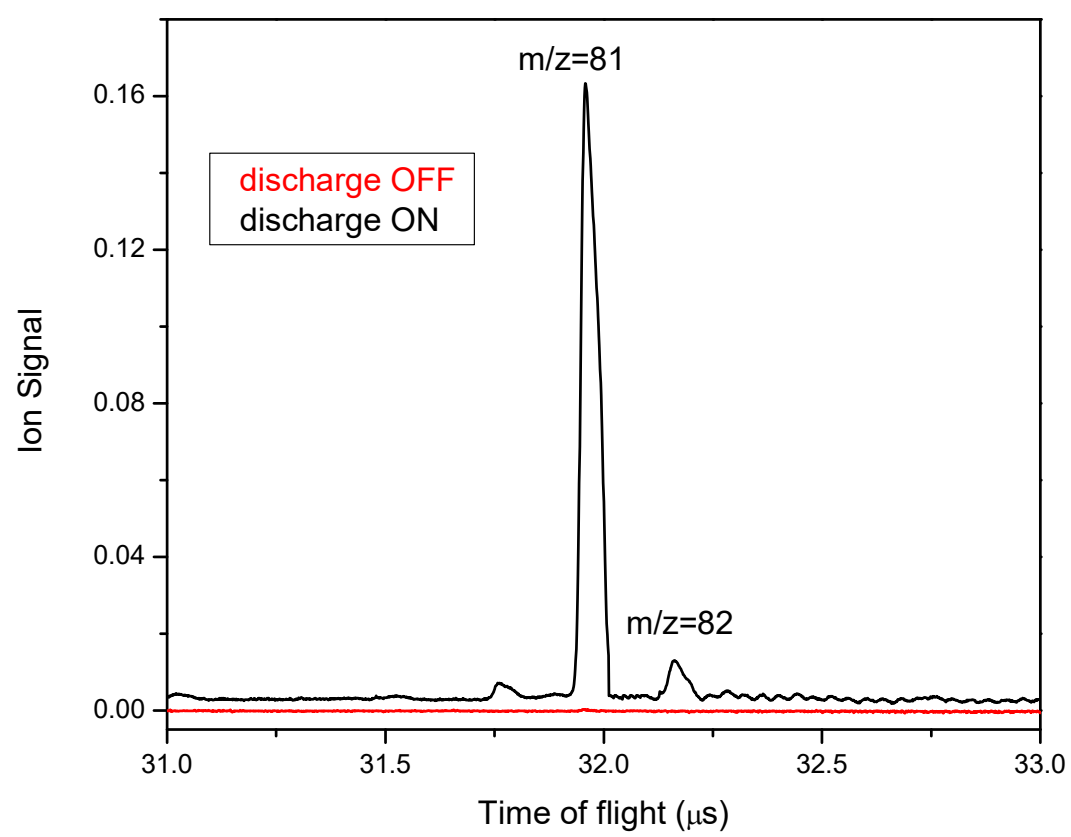

Figure 4. Mass spectra obtained for a mixture of $\mathrm{He}_{\mathrm{H}} \mathrm{H}_{2} /$ pyrimidine with the discharge source on (black) or off (red). The probe (ionization) laser is set to $353.8 \mathrm{~nm}$.

The electronic spectrum of the $\mathrm{PmH} \cdot$ radical is recorded by monitoring the intensity of the $\mathrm{m} / \mathrm{z}=81$ mass peak $\left(\mathrm{PmH}^{+}\right)$while scanning the probe (ionization) laser from the visible to the $\mathrm{UV}$, as displayed in Fig 5. Different groups of absorption bands can be clearly observed: a group at low energy (355 $379 \mathrm{~nm}$ or $3.5-3.27 \mathrm{eV}$ ) which consists of well-resolved narrow bands and a group at higher energies $(330-354 \mathrm{~nm}$ or $3.75-3.5 \mathrm{eV}$ ), which consists of broad vibronic bands with narrow spacings (see the inset in Fig 5). The lines between 296 and $330 \mathrm{~nm}$ correspond to the spectrum of the pyrimidine isomer containing a ${ }^{13} \mathrm{C}$ carbon atom (see Fig SI.3). No absorption is detected further to the blue, between 4.2 and $5.5 \mathrm{eV}$ (i.e. off the scale in Fig 5). 


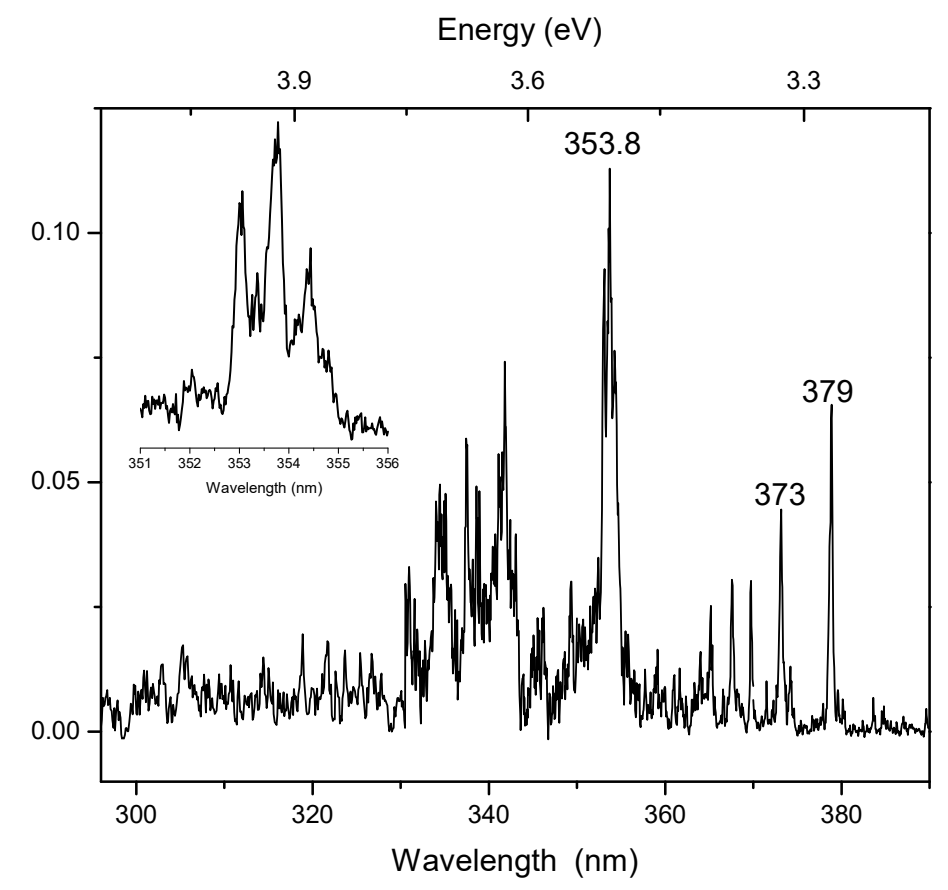

Figure 5. Electronic spectrum of the PmH• radical produced in the discharge source and cooled down in the supersonic expansion. The spectrum is obtained by resonance enhanced one-color two-photon ionization (R2PI). The inset shows the most intense line at $353.8 \mathrm{~nm}$ on an enlarged scale.

The two main band systems (the narrow band and broad band) can be due to either different states of the same species or different tautomers. The latter possibility was suggested previously for tautomers of several aromatic molecules where the protonation takes place on the aromatic ring. ${ }^{52}$ Analogously, the hydrogenation of Pm could take place at a $\mathrm{C}$-atom of the aromatic ring rather than at the $\mathrm{N}$-atom. As is discussed in the Supplementary Information (see Fig SI.4), UV - UV hole-burning (HB) experiments reveal that the transitions starting at $379 \mathrm{~nm}$ and $353.8 \mathrm{~nm}$ in Fig 5 are due to same species. The transitions at 353.8 and $342 \mathrm{~nm}$ could be due to different electronic states or to different vibrational levels of the electronic states detailed above. The profiles of these transitions are similar, which tends to favor their attribution to vibrational levels.

To aid the assignment of the experimental electronic spectrum of the $\mathrm{PmH}$ - radical, vertical excitation energies were calculated with the unrestricted $\mathrm{ADC}(2)$ method. The equilibrium geometry of the $\mathrm{PmH} \cdot$ radical is planar with an $\mathrm{NH}$ distance $R_{\mathrm{NH}}=1.014 \AA$. The vertical excitation energies and oscillator strengths of the five lowest doublet excited states are listed in Table 2. The singly occupied 
molecular orbital (SOMO) of the $\mathrm{PmH}^{\bullet}$ radical is a $\pi$ orbital, while the LUMO is a diffuse $\sigma^{*}$ orbital. The lowest excited state $\left(D_{1}\right)$, with a calculated excitation energy of $1.98 \mathrm{eV}(627 \mathrm{~nm})$, corresponds to the excitation from the SOMO to the lowest $\pi^{*}$ orbital. The $\mathrm{D}_{2}$ state, with an excitation energy of 2.67 $\mathrm{eV}(465 \mathrm{~nm})$, is the lowest $\pi \sigma^{*}$ state: its main configuration corresponds to an orbital transition from the SOMO to the LUMO (see Fig SI.2). The computed oscillator strengths of the lowest five excited states of $\mathrm{PmH} \bullet$ are very small, see Table 2 . The calculation did not take into account vibronic intensity borrowing effects from higher lying bright excited states and therefore likely underestimates the actual oscillator strengths.

Table 2. Vertical excitation energies (in $\mathrm{eV}$ ) and oscillator strengths (in parentheses) of the five lowest excited states of the PmH・ radical, calculated at the ADC(2) level.

\begin{tabular}{ll}
\hline State & Energy \\
\hline $\mathrm{D}_{1}\left(\pi \pi^{*}\right)$ & $1.98(0.001)$ \\
$\mathrm{D}_{2}\left(\pi \sigma^{*}\right)$ & $2.67(0.000)$ \\
$\mathrm{D}_{3}\left(\pi \sigma^{*}\right)$ & $3.48(0.001)$ \\
$\mathrm{D}_{4}\left(\pi \sigma^{*}\right)$ & $3.74(0.001)$ \\
$\mathrm{D}_{5}\left(\pi \pi^{*}\right)$ & $3.99(0.005)$ \\
\hline
\end{tabular}

We assign the first experimentally observed transition starting at $3.27 \mathrm{eV}(379 \mathrm{~nm})$ to the $\mathrm{D}_{5}\left(\pi \pi^{*}\right)$ state with a calculated vertical excitation energy of $3.99 \mathrm{eV}$ on account of the sharpness of the vibronic lines which is characteristic of a bound ${ }^{2} \pi \pi^{*}$ state. This implies that the excitation energy of the $\mathrm{D}_{5}\left(\pi \pi^{*}\right)$ state is significantly overestimated by the unrestricted $\mathrm{ADC}(2)$ method. The transitions at around 3.50 $\mathrm{eV}(353.8 \mathrm{~nm})$ and $3.65 \mathrm{eV}(340 \mathrm{~nm})$ are assigned to the ${ }^{2} \pi \sigma^{*}$ states $\mathrm{D}_{3}$ and $\mathrm{D}_{4}$, calculated at $3.48 \mathrm{eV}$ and $3.74 \mathrm{eV}$. For these states, the agreement between theory and experiment is very good. The diffuseness of these bands is consistent with the assignment to $\pi \sigma^{*}$ states. The observed intensities do not correlate well with the calculated oscillator strengths, which may indicate the importance of vibronic intensity borrowing effects. 
The calculated ionization potential of the $\mathrm{PmH} \cdot$ radical is $5.59 \mathrm{eV}\left(45090 \mathrm{~cm}^{-1}\right.$ or $\left.222 \mathrm{~nm}\right)$, taking into account the difference in the zero-point energies. This prediction agrees with the fact that the ionization threshold has not been observed within the spectral range covered by the present experiment. This finding also implies that two-photon absorption is necessary to detect the $\mathrm{PmH} \cdot$ radical. For this reason, the first two exited states $\mathrm{D}_{1}$ and $\mathrm{D}_{2}$ of the $\mathrm{PmH} \cdot$ radical cannot be observed in the present experiment.

\subsection{Experimental investigation of excited-state $\mathrm{H}$-atom transfer in $\mathrm{Pm}-\left(\mathrm{H}_{2} \mathrm{O}\right)_{n}$ clusters}

The distribution of cluster size $(\mathrm{s})$ of $\mathrm{Pm}-\left(\mathrm{H}_{2} \mathrm{O}\right)_{n}$ clusters is not known explicitly. Clusters with size $n>2$ are not detected in the expansion even when optimizing the expansion conditions for larger clusters (in general, cluster size increases with increasing backing pressure). It is likely that clusters with $\mathrm{n}>2$ have lifetimes that are too short to allow ionization with our ns lasers. However, since the variation of the $\mathrm{PmH} \bullet$ signal as a function of the backing pressure is similar to that reported for the $\mathrm{PyH} \cdot$ radical, it is anticipated that large clusters should be involved in the reaction, as was the case for $\mathrm{Py}-\left(\mathrm{H}_{2} \mathrm{O}\right)_{n}$ clusters. $^{10}$

Both Pm and Pm- $\left(\mathrm{H}_{2} \mathrm{O}\right)_{n}$ clusters exhibit a broad absorption band around $240 \mathrm{~nm}$ (see Fig 3 and Fig SI.5). At this wavelength, $\mathrm{PmH} \cdot$ radicals do not absorb, as discussed above. On the other hand, $\mathrm{PmH} \cdot$ radicals have an absorption band at $353.8 \mathrm{~nm}$, where Pm and its complexes with water do not absorb. This observation suggests that the photoinduced reaction in Pm-water clusters yielding PmH $\bullet$ radicals can be selectively explored by exciting the clusters at $240 \mathrm{~nm}$ and probing the formation of the radical at $353.8 \mathrm{~nm}$. The Pm- $\left(\mathrm{H}_{2} \mathrm{O}\right)_{n}$ clusters produced in the supersonic jet were therefore excited at $240 \mathrm{~nm}$ and the $\mathrm{PmH} \cdot$ radical was probed by ionization at $353.8 \mathrm{~nm}$, see Scheme 1 . 


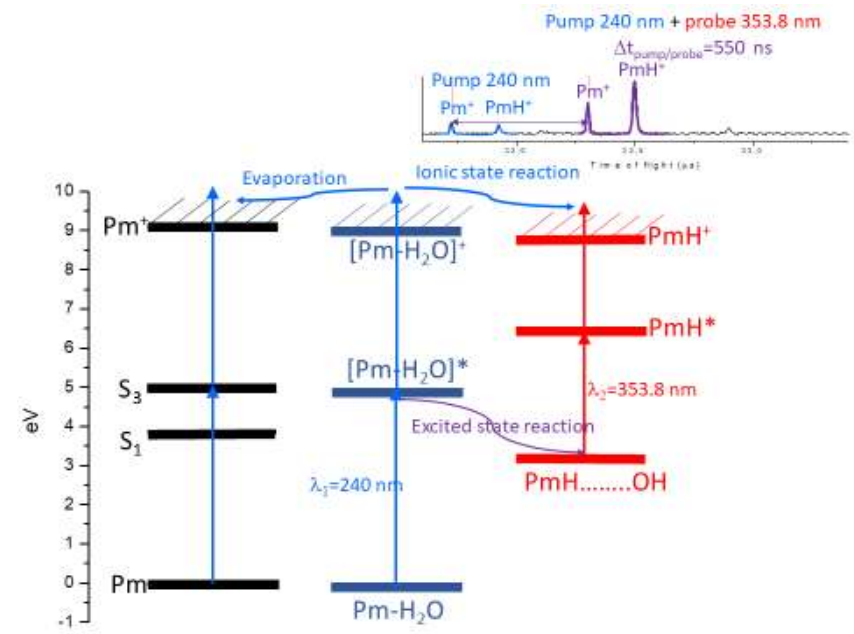

Scheme 1: Reaction scheme for Pm- $\left(\mathrm{H}_{2} \mathrm{O}\right)_{n}$ clusters. $\mathrm{Pm}$ and $\mathrm{Pm}-\left(\mathrm{H}_{2} \mathrm{O}\right)_{n}$ are excited with a single 240 $\mathrm{nm}$ photon to the bright ${ }^{1} \pi \pi^{*}$ state $\left(\mathrm{S}_{3}\right)$. Excited $\mathrm{Pm}-\left(\mathrm{H}_{2} \mathrm{O}\right)_{n}{ }^{*}$ clusters may absorb a second $240 \mathrm{~nm}$ photon leading to ionic clusters $\mathrm{Pm}-\left(\mathrm{H}_{2} \mathrm{O}\right)_{n}{ }^{+}$that can either evaporate water molecules or react to give $\mathrm{PmH} \mathrm{H}^{+}$ionic fragments (blue arrows). Excited $\mathrm{Pm}-\left(\mathrm{H}_{2} \mathrm{O}\right)_{n}{ }^{*}$ clusters may also react to yield $\mathrm{Pm} \mathrm{H}^{\bullet}$ and $\mathrm{OH}^{\bullet}$ radicals (violet arrow), where $\mathrm{PmH}^{\bullet}$ is probed via two photon ionization at $353.8 \mathrm{~nm}$ (red arrows). These experiments were performed within the extraction region of the TOF mass spectrometer held at a constant voltage.

The delay between pump and probe lasers is chosen to be $550 \mathrm{~ns}$ in order to discriminate the $\mathrm{PmH}^{\bullet}$ radical from the ${ }^{13} \mathrm{C}$ isotope of pyrimidine, and to discriminate the reaction in the excited state of neutral clusters from a possible reaction in cationic clusters due to two-photon absorption at $240 \mathrm{~nm}$ (the latter process is reflected by the $\mathrm{PmH}^{+}$peak in the upper panel of Fig 6). Besides, this delay precludes absorption of the probe laser by excited states of the clusters which have much shorter lifetimes. The $\mathrm{PmH}^{+}$ions generated by ionization of $\mathrm{PmH} \cdot$ with the probe laser are observed $550 \mathrm{~ns}$ after the $\mathrm{PmH}^{+}$ ions produced solely by the pump laser $(240 \mathrm{~nm})$, since the $t=0$ setting for the time of flight is synchronized with the pump laser. 


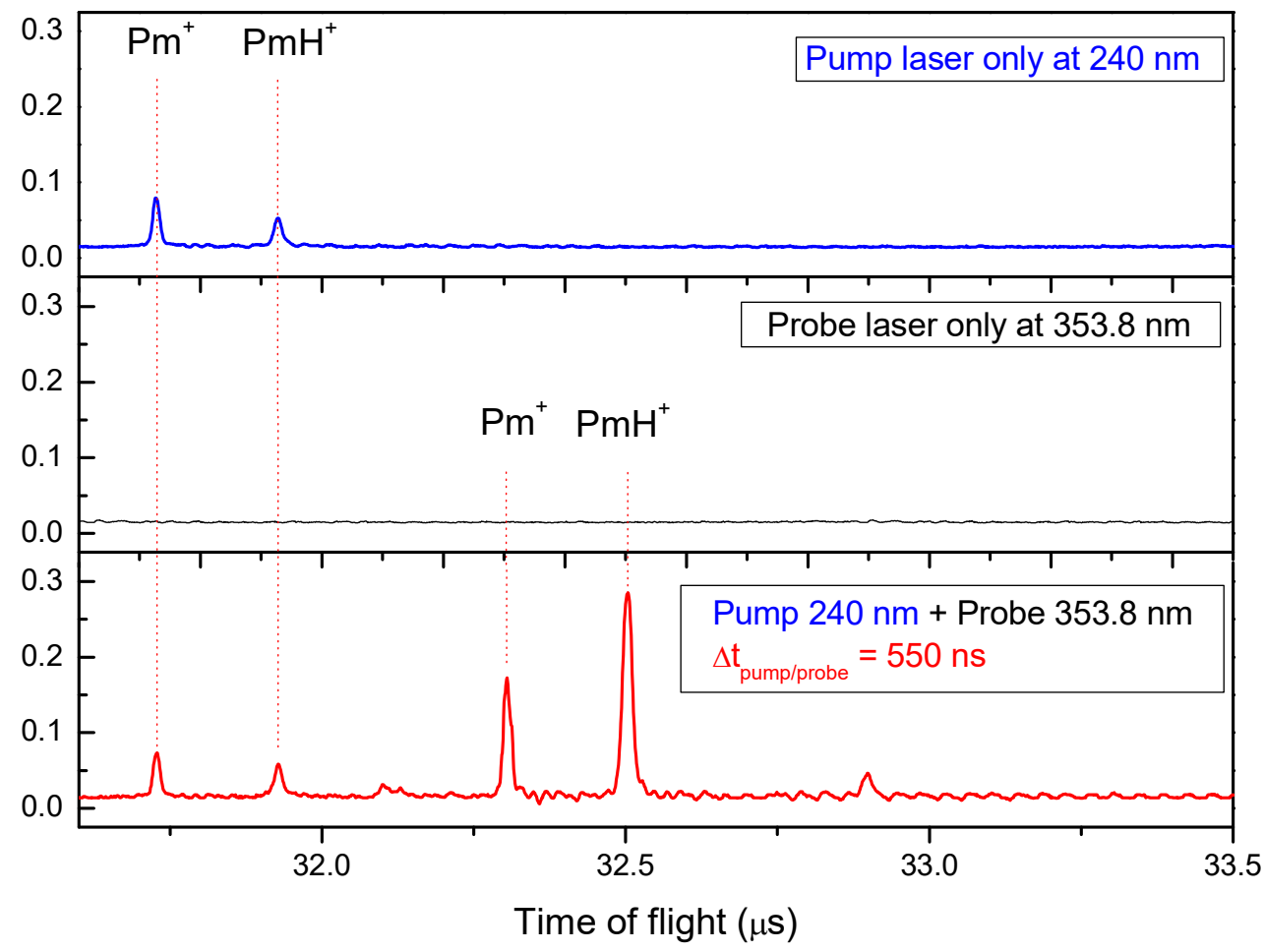

Figure 6. Mass spectra recorded after excitation of Pm- $\left(\mathrm{H}_{2} \mathrm{O}\right)_{n}$ clusters. Upper trace: pump laser only, at $240 \mathrm{~nm} ; \mathrm{Pm}-\left(\mathrm{H}_{2} \mathrm{O}\right)_{n}$ clusters are excited and the $\mathrm{PmH}^{+}$ion is produced (by reaction in cationic clusters) through one-color two-photon absorption. Middle trace: probe laser only, at $353.8 \mathrm{~nm}$; no ion signal is observed, since neither Pm nor Pm- $\left(\mathrm{H}_{2} \mathrm{O}\right)_{n}$ absorb at this wavelength. Lower trace: pump $(240 \mathrm{~nm})$ and probe $(353.8 \mathrm{~nm})$ lasers, with the probe laser delayed by $550 \mathrm{~ns}$; the most intense peak is the PmH $\mathrm{H}^{+}$ion produced by a PCET reaction in the neutral clusters (excited by one photon at 240 nm) followed by ionization of the product PmH• radical (via a two-photon process at $353.8 \mathrm{~nm}$ ).

Evidence for the formation of the $\mathrm{PmH}^{\bullet}$ radical is presented in Fig 6. The $\mathrm{PmH}^{+}$signal is absent if the pump laser is off and the probe laser is on (middle trace). When both lasers are present (lower trace), the $\mathrm{PmH} \cdot$ radical, which is detected via its ionization product $\mathrm{PmH}^{+}$, gives rise to the most intense peak (see Scheme 1). The H-atom transfer reaction in excited states of Pm-water clusters is thus clearly confirmed.

In the upper trace of Fig. 6, a small amount of the $\mathrm{PmH}^{+}$ion is observed through a one-color twophoton ionization scheme with only the pump laser at $240 \mathrm{~nm}$. This signal does not correspond to excitation/ionization of the $\mathrm{PmH} \bullet$ radical, which does not absorb in this spectral region, and thus is not 
related to the H-atom transfer reaction in the excited states of neutral Pm-water clusters. The signal, rather, comes from an H-atom transfer reaction in ionic Pm-water clusters (see Scheme 1, blue arrows). The spectral signatures of the $\mathrm{H}$-atom transfer reaction in the (neutral) excited state or in the ionic state of $\mathrm{Pm}-\left(\mathrm{H}_{2} \mathrm{O}\right)_{n}$ clusters are totally different. The $\mathrm{PmH}^{+}$signal arising from the ionic reaction appears at wavelengths corresponding to the two-photon absorption of $\mathrm{Pm}-\left(\mathrm{H}_{2} \mathrm{O}\right)_{n}$ clusters, between $230 \mathrm{~nm}$ and $245 \mathrm{~nm}$ (see Fig SI.5), while the excited-state reaction in neutral pyrimidine-water clusters yields $\mathrm{PmH} \bullet$ radicals, which cannot be ionized in the 230 - $245 \mathrm{~nm}$ spectral region, but will be ionized in the $320-380$ $\mathrm{nm}$ spectral region, as observed when $\mathrm{PmH} \bullet$ radicals produced in the discharge source are ionized (Fig $5)$.

Aside from the signatures in mass spectra at fixed wavelengths (Fig. 6), the $\mathrm{PmH} \cdot$ radical produced via excited-state reactivity in $\mathrm{Pm}-\left(\mathrm{H}_{2} \mathrm{O}\right)_{n}$ clusters can be detected through a two-photon ionization scheme in the spectral region where it absorbs. In Fig 7, we present the pump/probe PmH• action spectrum (with $\mathrm{PmH} \cdot$ the product of an excited-state reaction in $\mathrm{Pm}-\left(\mathrm{H}_{2} \mathrm{O}\right)_{n}$ clusters) compared to the spectrum obtained for the cold species generated in the discharge source. This comparison unambiguously confirms that the $\mathrm{PmH}^{+}$signal detected with the probe laser is due to the ionization of the $\mathrm{PmH} \cdot$ radical. It can be observed that the peaks in the action spectrum resulting from the reaction in clusters are broadened in comparison with the spectrum of the cold species produced in the discharge source, which indicates that the $\mathrm{PmH} \cdot$ reaction products in clusters are generated with significant internal energy. 


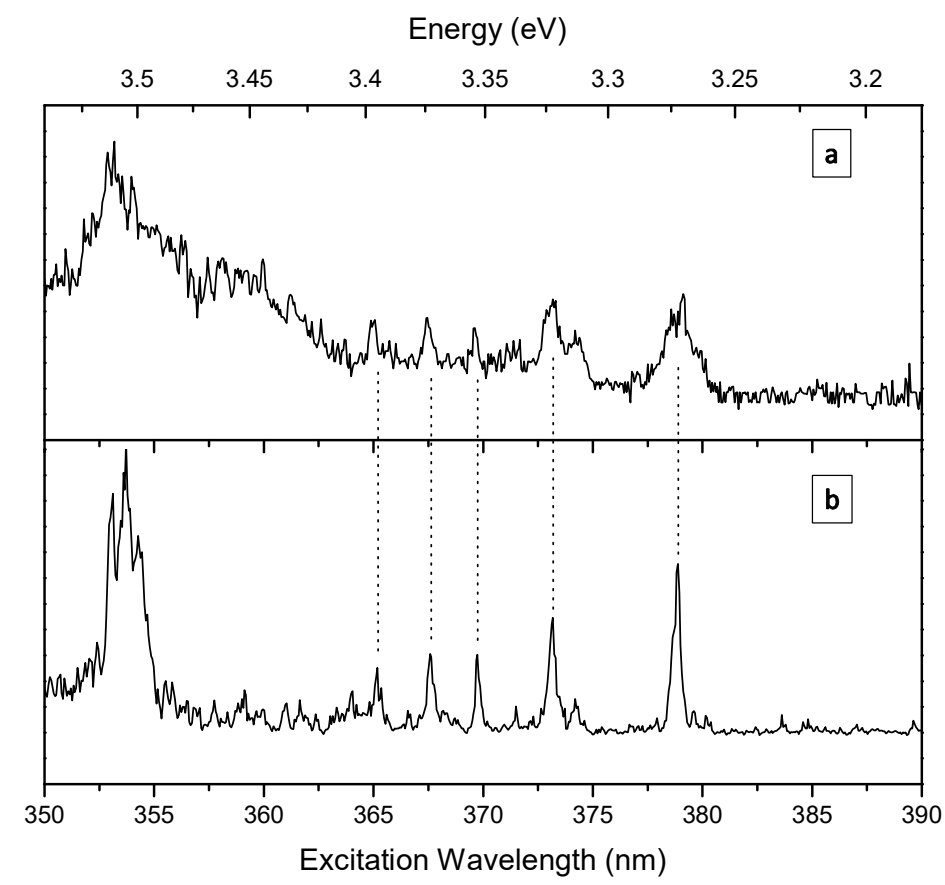

Figure 7. Comparison between PmH• spectra obtained via two-photon ionization for (a) $\mathrm{PmH}$ produced in the $\mathrm{H}$-atom transfer reaction in $\mathrm{Pm}-\left(\mathrm{H}_{2} \mathrm{O}\right)_{n}$ clusters, excited at $240 \mathrm{~nm}$; and (b) cold $\mathrm{PmH}$ • produced in the discharge source (from Fig 5).

\subsection{Computational investigation of excited-state $\mathrm{PCET}$ in $\mathrm{Pm}-\mathrm{H}_{2} \mathrm{O}$ and $\mathrm{Pm}-\left(\mathrm{H}_{2} \mathrm{O}\right)_{4}$ clusters}

We have performed quasi-classical trajectory surface-hopping simulations of the photoinduced reaction dynamics in the $\mathrm{Pm}-\mathrm{H}_{2} \mathrm{O}$ and $\mathrm{Pm}-\left(\mathrm{H}_{2} \mathrm{O}\right)_{4}$ complexes. For the simple $\mathrm{Pm}-\mathrm{H}_{2} \mathrm{O}$ complex, it is possible to compute one-dimensional and two-dimensional relaxed energy profiles which are helpful for the interpretation of the reaction mechanism. The Pm- $(\mathrm{H} 2 \mathrm{O})_{4}$ complex is a more realistic model of the photochemical water oxidation reaction occurring in Pm-water clusters. Briefly, the simulations for the Pm- $\left(\mathrm{H}_{2} \mathrm{O}\right)_{4}$ complex provide evidence of three reaction mechanisms following excitation of the bright ${ }^{1} \pi \pi^{*}$ state of Pm: (i) radiationless relaxation of the $S_{3}\left(\pi \pi^{*}\right)$ state via the $S_{2}\left(n \pi^{*}\right)$ state to the $S_{1}\left(n \pi^{*}\right)$ state on a time scale of about $100 \mathrm{fs}$, (ii) H-atom transfer from water to Pm occurring on about the same timescale, yielding ground-state $\mathrm{PmH} \cdots \cdot \mathrm{OH} \cdot\left(\mathrm{H}_{2} \mathrm{O}\right)_{3}$ biradicals, and (iii) radiationless decay of the $\mathrm{S}_{1}\left(\mathrm{n} \pi^{*}\right)$ state to the $\mathrm{S}_{0}$ state of $\mathrm{Pm}$ on longer timescales (picoseconds and beyond). The $\mathrm{H}$-atom transfer reaction is found to occur only within the first $150 \mathrm{fs}$ in competition with the electronic relaxation from the $\mathrm{S}_{3}\left(\pi \pi^{*}\right)$ to the $\mathrm{S}_{1}\left(\mathrm{n} \pi^{*}\right)$ state. 


\subsubsection{PE profiles and $\mathrm{PE}$ surface for the $\mathrm{Pm}-\mathrm{H}_{2} \mathrm{O}$ cluster}

To assist the interpretation of the dynamics simulations, we computed one-dimensional and twodimensional relaxed energy profiles for the excited-state $\mathrm{H}$-atom transfer reaction in the $\mathrm{Pm}-\mathrm{H}_{2} \mathrm{O}$ complex. These data are also useful at a qualitative level for the interpretation of the H-atom transfer reaction in the $\mathrm{Pm}-\left(\mathrm{H}_{2} \mathrm{O}\right)_{4}$ cluster.

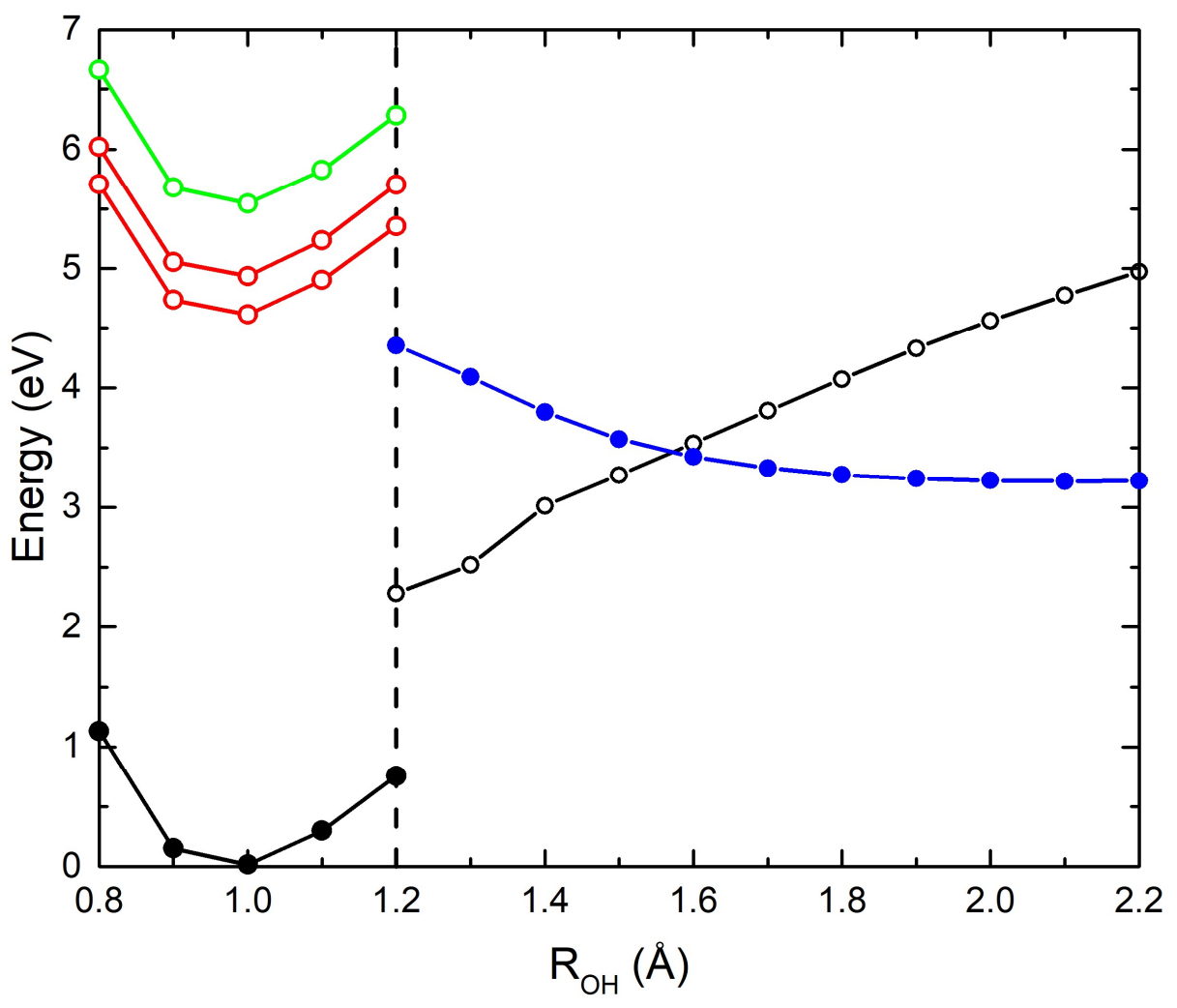

Figure 8. Energy profiles of the electronic ground state and the lowest excited states of the $\mathrm{Pm}-\mathrm{H}_{2} \mathrm{O}$ complex. Solid dots indicate that the geometry was optimized for this electronic state. Hollow dots represent energies calculated at geometries which were optimized for another electronic state. Black: electronic ground state; green: excited states of $A^{\prime}$ symmetry; red: excited states of A" symmetry; blue: CT state. 
Electronic energy profiles along the relaxed scan for the $\mathrm{H}$-atom transfer reaction from $\mathrm{H}_{2} \mathrm{O}$ to $\mathrm{Pm}$ in the Pm- $\mathrm{H}_{2} \mathrm{O}$ complex are shown in Fig 8. The driving coordinate $R_{\mathrm{OH}}$ is defined as the bond length of the $\mathrm{OH}$ group of the water molecule involved in hydrogen bonding with the $\mathrm{N}$-atom of $\mathrm{Pm}$. For small values of $R_{\mathrm{OH}}(<1.2 \AA)$, the complex consists of a water molecule which is hydrogen-bonded to the Pm molecule (see Fig 1(a)). For large $R_{\mathrm{OH}}(>1.2 \AA$ ), on the other hand, the complex consists of a hydrogenbonded $\mathrm{PmH} \cdot \cdots \mathrm{OH} \cdot$ radical pair. For small $R_{\mathrm{OH}}$, the relaxed scan has been computed in the electronic ground state and the excited-state energy profiles are found to be parallel to the energy profile of the electronic ground state, representing locally excited $n \pi^{*}$ (red) and $\pi \pi^{*}$ (green) states of Pm. For $R_{\mathrm{OH}}>$ $1.2 \AA$, the relaxed scan has been computed for the lowest state of $\mathrm{A}^{\prime \prime}$ symmetry and the energy of this state is shown in the right part of the graph (blue curve with solid dots). It represents a CT state involving the transition of an electron from a $\mathrm{p}_{\mathrm{x} / \mathrm{y}}$ orbital of the hydrogen-bonded water molecule to the $\pi^{*}$ orbital of Pm. The energy of the closed-shell $\mathrm{S}_{0}$ state at these CT-state-optimized geometries is given by the open black circles. While the energy of the $\mathrm{CT}$ state decreases with increasing $R_{\mathrm{OH}}$, the energy of the closed-shell $\mathrm{S}_{0}$ state increases steeply with $R_{\mathrm{OH}}$. As a result, the energy profile of the $\mathrm{CT}$ state crosses the ground-state energy profile with increasing $R_{\mathrm{OH}}$ and becomes the electronic state of lowest energy for $R_{\mathrm{OH}}>1.58 \AA$, see Fig 8 . In this region of $R_{\mathrm{OH}}$, the electronic charge transfer is neutralized by the transferred proton. The dramatic stabilization of the energy of the CT state by proton transfer from the water molecule to Pm illustrates the pronounced driving force for proton transfer once the CT state is populated by hole transfer from $\mathrm{Pm}$ to the $\mathrm{H}_{2} \mathrm{O}$ molecule. This interplay of electron transfer and proton transfer is usually termed proton-coupled electron transfer (PCET) in the literature. ${ }^{53}$ The net effect is the transfer of an H-atom. Herein, we use the terms "H-atom transfer" and "PCET" synonymously. Due to the strong driving force and the low mass of the proton, the PCET reaction can compete with ultrafast radiationless deactivation pathways of the $n \pi^{*}$ and $\pi \pi^{*}$ excited states of Pm (see below). The crossing of the energy of the CT state of $\mathrm{A}^{\prime \prime}$ symmetry with the energy of the $\mathrm{S}_{0}$ state of $\mathrm{A}^{\prime}$ symmetry in Fig 8 is a symmetry-allowed energy crossing which becomes a CI when out-of-plane vibrational modes are taken into account. 


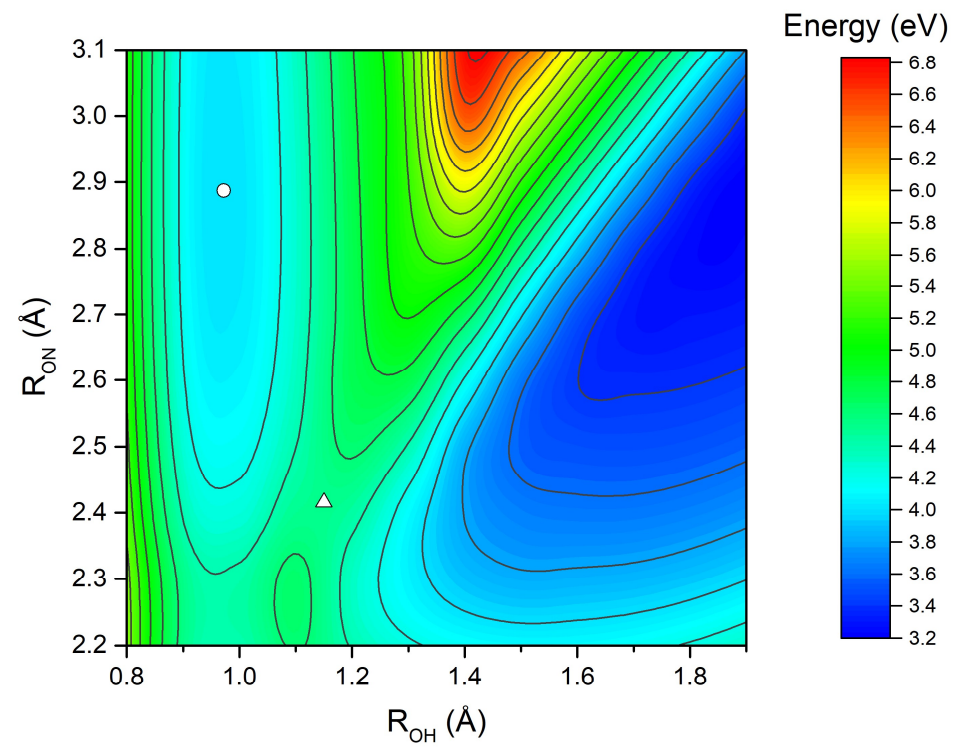

Figure 9. Relaxed 2D PE surface of the lowest state of $A^{\prime \prime}$ symmetry of the Pm- $\mathrm{H}_{2} \mathrm{O}$ complex, computed with the ADC(2) method. The contour lines are spaced by $0.2 \mathrm{eV}$. The circle marks the equilibrium geometry of the lowest ${ }^{l} n \pi^{*}$ state. The triangle marks the saddle point of the PCET reaction.

A relaxed two-dimensional PE surface of the lowest state of A" symmetry (which is the $n \pi^{*}$ state in the Franck-Condon region) of the $\mathrm{Pm}-\mathrm{H}_{2} \mathrm{O}$ complex spanned by the reaction coordinates $R_{\mathrm{OH}}$ and $R_{\mathrm{ON}}$ (the distance between the $\mathrm{O}$-atom of water and the $\mathrm{N}$-atom of $\mathrm{Pm}$ ) is displayed as contour plot in Fig 9. This surface provides a more complete picture of the PCET reaction in the $\mathrm{Pm}-\mathrm{H}_{2} \mathrm{O}$ complex. The energy minimum located at small $\mathrm{OH}$ bond length (upper-left part) corresponds to the minimum of the lowest locally excited $n \pi^{*}$ state of the chromophore (it corresponds to the left part of Fig 8 ). The deep valley for large $\mathrm{OH}$ distance (right part) corresponds to the $\mathrm{PmH} \cdots \cdots \mathrm{OH} \bullet$ biradical. The region of high energy (colored in red) represents the lower cone of a CI with the next higher excited state. The saddle point (marked by the triangle in Fig 9) separating the local $S_{1}$ minimum from the valley leading to the biradical is located at $R_{\mathrm{OH}}=1.15 \AA, R_{\mathrm{ON}}=2.42 \AA$, at an estimated energy of $4.54 \mathrm{eV}$. The height of the barrier relative to the local $\mathrm{S}_{1}$ energy minimum $(4.07 \mathrm{eV})$ is $0.50 \mathrm{eV}$, which is about $0.30 \mathrm{eV}$ above the zeropoint energy of the $\mathrm{OH}$ stretching vibration in the $\mathrm{S}_{1}$ state. 


\subsubsection{Trajectory surface-hopping dynamics simulations}

The trajectories were started in the bright $S_{3}\left(\pi \pi^{*}\right)$ adiabatic state of Pm with initial positions and momenta sampled from the thermal Wigner distribution as described in the computational methods section. The time-dependent population probabilities of the four lowest adiabatic excited electronic singlet states and the ground state are plotted in Fig 10 up to 500 fs for the $\mathrm{Pm}-\mathrm{H}_{2} \mathrm{O}$ and $\mathrm{Pm}-\left(\mathrm{H}_{2} \mathrm{O}\right)_{4}$ complexes. Overall, the two complexes exhibit similar electronic population dynamics. The initial population in the $S_{3}\left(\pi \pi^{*}\right)$ state generated by the pump laser is initially transferred to the $S_{2}\left(n \pi^{*}\right)$ state and subsequently to the $S_{1}\left(n \pi^{*}\right)$ state within about $100 \mathrm{fs}$. Weak recurrences of the $S_{2}$ population in the $\mathrm{Pm}-\mathrm{H}_{2} \mathrm{O}$ complex (green curve in Fig 10(a)) are reduced in the Pm- $\left(\mathrm{H}_{2} \mathrm{O}\right)_{4}$ complex (green curve in Fig 10(b)). The main difference between the two complexes is in the population of the $\mathrm{S}_{0}$ state (black line). In the $\mathrm{Pm}-\mathrm{H}_{2} \mathrm{O}$ complex, no population is transferred to the $\mathrm{S}_{0}$ state within the first $200 \mathrm{fs}$. In the Pm$\left(\mathrm{H}_{2} \mathrm{O}\right)_{4}$ complex, on the other hand, the $\mathrm{S}_{0}$ population increases around $50 \mathrm{fs}$, during the decay of the $\mathrm{S}_{3}$ and $\mathrm{S}_{2}$ populations. As will be discussed below, this short-time increase of the $\mathrm{S}_{0}$ population in the Pm$\left(\mathrm{H}_{2} \mathrm{O}\right)_{4}$ complex arises from $\mathrm{H}$-atom transfer processes which generate biradicals in the electronic ground state. These $\mathrm{H}$-atom transfer reactions die out when the electron population has settled in the $\mathrm{S}_{1}$ state after about $100 \mathrm{fs}$. The $\mathrm{S}_{1}$ population decays slowly (on a timescale of picoseconds) by internal conversion to the $\mathrm{S}_{0}$ state. Interestingly, this slow decay is more pronounced for the $\mathrm{Pm}-\left(\mathrm{H}_{2} \mathrm{O}\right)_{4}$ complex than for the $\mathrm{Pm}-\mathrm{H}_{2} \mathrm{O}$ complex. The $\mathrm{S}_{0}$ population reaches about $13 \%$ at 500 fs in the $\mathrm{Pm}-\left(\mathrm{H}_{2} \mathrm{O}\right)_{4}$ complex, while it reaches only $8 \%$ in the $\mathrm{Pm}-\mathrm{H}_{2} \mathrm{O}$ complex. At $t=500 \mathrm{fs}$, about $86 \%(82 \%)$ of the electronic population is in the $\mathrm{S}_{1}$ state for the $\mathrm{Pm}-\mathrm{H}_{2} \mathrm{O}\left(\mathrm{Pm}-\left(\mathrm{H}_{2} \mathrm{O}\right)_{4}\right)$ complex. The distribution of the adiabatic electronic state populations at the end of the simulation interval is shown on the right hand side of Fig 10. 

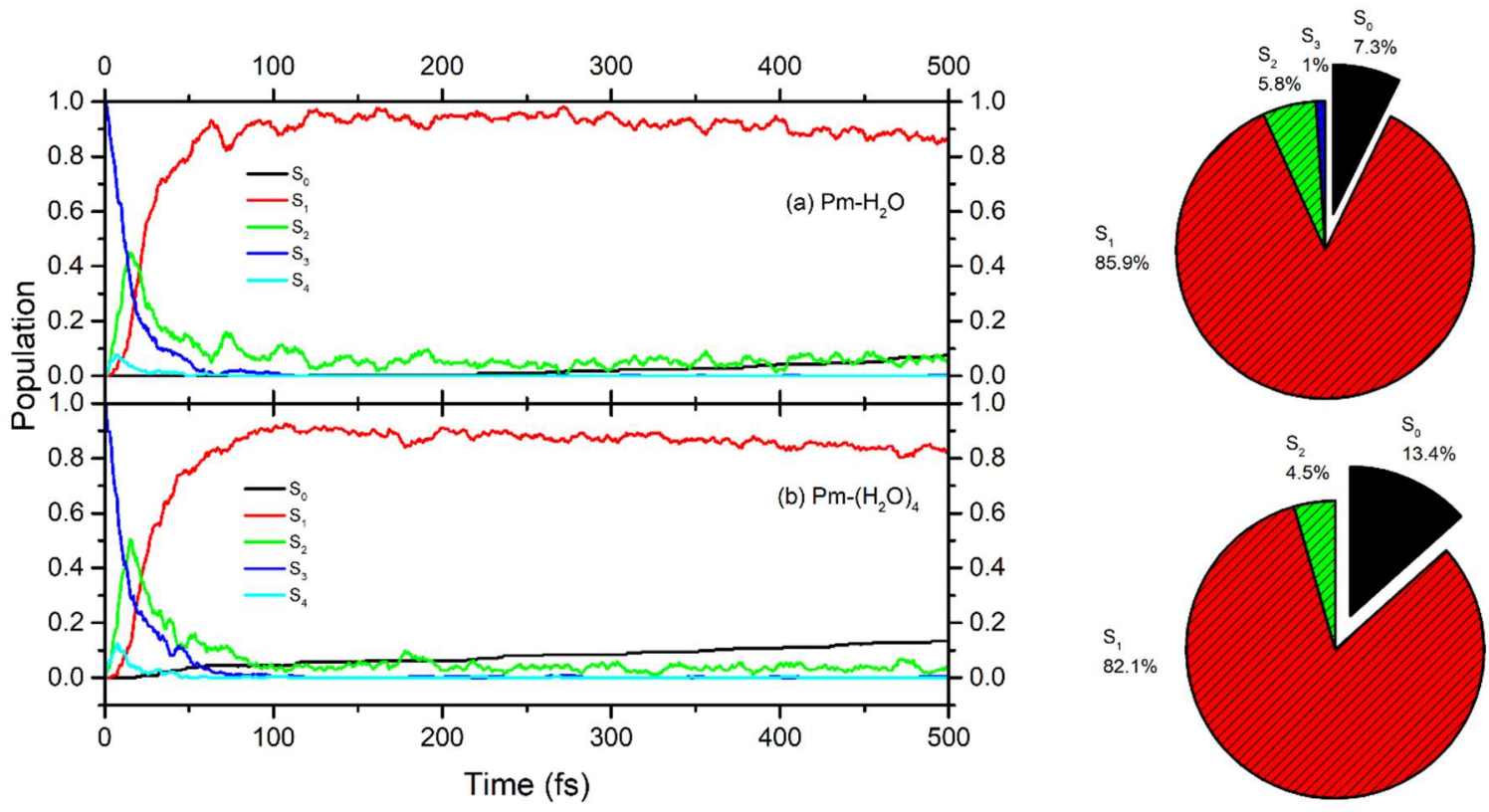

Figure 10. Population probabilities of the four lowest energy excited states $\left(S_{1}\right.$ to $\left.S_{4}\right)$ and the $S_{0}$ state for (a) the Pm- $\mathrm{H}_{2} \mathrm{O}$ complex and (b) the Pm- $\left(\mathrm{H}_{2} \mathrm{O}\right)_{4}$ complex. The population distribution at $t=500 \mathrm{fs}_{\mathrm{S}}$ is shown on the right hand side.

The $\mathrm{H}$-atom transfer dynamics is monitored by the time evolution of the bond length between the acceptor $\mathrm{N}$-atom of $\mathrm{Pm}$ and the $\mathrm{H}$-atom of the hydrogen-bonded water molecule. In the $\mathrm{Pm}-\mathrm{H}_{2} \mathrm{O}$ complex, no persistent $\mathrm{H}$-atom transfer processes could be identified. In the Pm- $\left(\mathrm{H}_{2} \mathrm{O}\right)_{4}$ complex, 11 out of 224 trajectories $(6 \%)$ lead to sustained proton transfer from the water cluster to Pm. The time evolution of the distances between the transferred $\mathrm{H}$-atom and the accepting $\mathrm{N}$-atom of $\mathrm{Pm}$ for the ensemble of trajectories of the $\mathrm{Pm}-\left(\mathrm{H}_{2} \mathrm{O}\right)_{4}$ complex within the first $100 \mathrm{fs}$ is presented in Fig 11. A persistent small value of the $\mathrm{NH}$ distance $(\approx 1.0 \AA)$ indicates that a successful $\mathrm{H}$-atom transfer reaction from the hydrogen-bonded water molecule to the Pm chromophore, whereas intermediate $(\approx 1.5-2.0$ $\AA$ ) or overall increasing $\mathrm{NH}$ distances indicate non-reactive trajectories. Large oscillations of the $\mathrm{NH}$ bond length indicate large excess energy in the $\mathrm{NH}$ vibration after relaxation to the electronic ground state. 


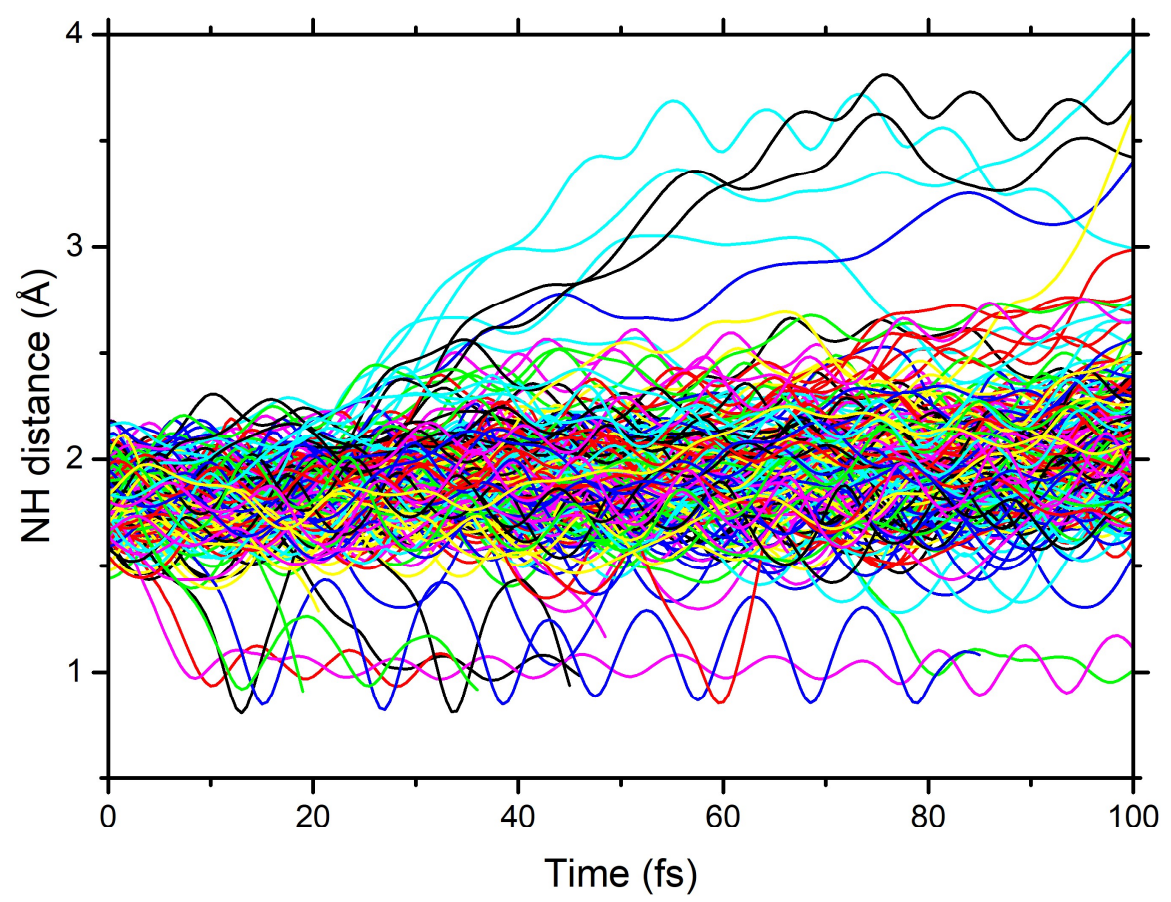

Figure 11. NH bond lengths of the ensemble of trajectories for the Pm- $\left(\mathrm{H}_{2} \mathrm{O}\right)_{4}$ complex. An oscillating $\mathrm{NH}$ distance around 1.0 A indicates a successful H-atom transfer from water to Pm. 


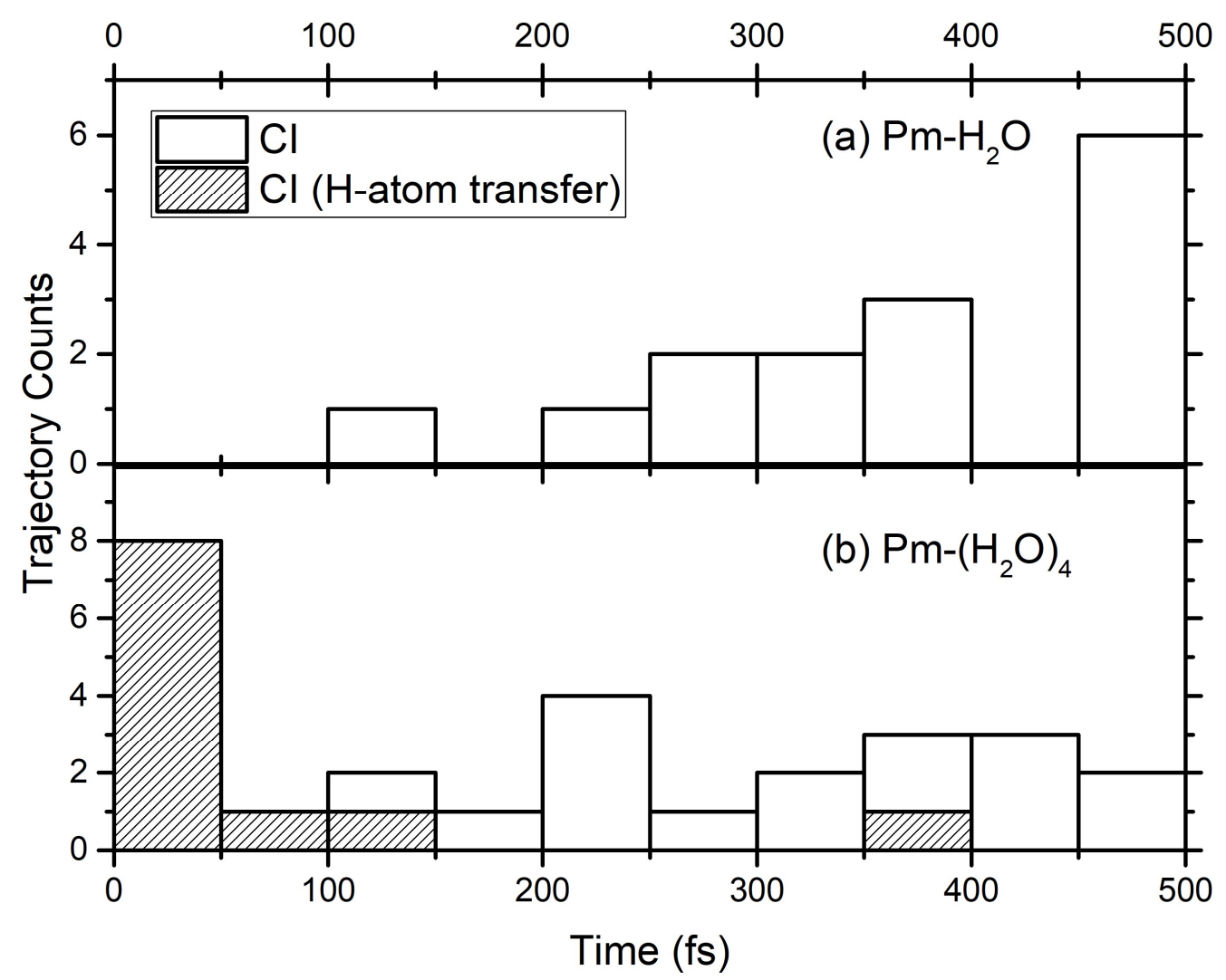

Figure 12. Histogram recording hits of $\mathrm{S}_{1}-\mathrm{S}_{0} \mathrm{CIs}$ for (a) the $\mathrm{Pm}-\mathrm{H}_{2} \mathrm{O}$ complex and (b) the Pm- $\left(\mathrm{H}_{2} \mathrm{O}\right)_{4}$ complex. CIs located in the non-hydrogen-transferred region are represented by white boxes, those located in the hydrogen-transferred region are marked by hatched boxes.

Histograms recording all hits of $\mathrm{S}_{1}-\mathrm{S}_{0}$ CIs by trajectories (see Section 3 for details) in the $\mathrm{Pm}-\mathrm{H}_{2} \mathrm{O}$ and $\mathrm{Pm}-\left(\mathrm{H}_{2} \mathrm{O}\right)_{4}$ complexes are shown in Fig 12. The events represented by white boxes represent relaxation to the electronic ground state at CIs which do not involve proton transfer (internal conversion within $\mathrm{Pm}$ ). The events shown by hatched boxes represent $\mathrm{H}$-atom transfer reactions producing groundstate biradicals. They are responsible for the increase of the $S_{0}$ population near 50 fs in Fig. 10(b). Interestingly, most of the successful $\mathrm{H}$-atom transfer events occur within the first 50 fs during and in competition with the radiationless deactivation of the $S_{3}$ and $S_{2}$ states of Pm.

After about $200 \mathrm{fs}$, most of the electronic population resides in the $S_{1}$ electronic state (see Fig 10) and the trajectories gradually relax towards the local minimum of the $\mathrm{S}_{1}$ electronic PE surface. PCET from this relaxed distribution requires tunneling through the barrier of about $0.5 \mathrm{eV}$ on the $\mathrm{S}_{1}$ surface 
(see Fig 9) and is expected to take place on picosecond to nanosecond time scales. There exists a single trajectory in the Pm- $\left(\mathrm{H}_{2} \mathrm{O}\right)_{4}$ complex with a late proton transfer event at $t=361.5 \mathrm{fs}$. The mechanism of this delayed proton transfer reaction is a reorganization within the $\left(\mathrm{H}_{2} \mathrm{O}\right)_{4}$ cluster which precedes the proton transfer.

We analyzed in detail all 11 trajectories undergoing proton transfer in the $\mathrm{Pm}-\left(\mathrm{H}_{2} \mathrm{O}\right)_{4}$ complex. A fluctuation of the $\mathrm{N} \cdots \mathrm{H}-\mathrm{O}$ hydrogen bond length prior to electron transfer from water to $\mathrm{Pm}$ is a characteristic feature of these trajectories. After the electron transfer, the proton of the hydrogen-bonded water molecule is driven from water to Pm, which neutralizes the electronic charge separation, resulting in a neutral biradical. To illustrate a typical $\mathrm{H}$-atom transfer process in the $\mathrm{Pm}-\left(\mathrm{H}_{2} \mathrm{O}\right)_{4}$ complex, a detailed analysis of a representative trajectory is presented in Fig 13. The time evolution of the NH distance in Fig 13(c) reveals a proton transfer event at about 6 fs $(\mathrm{NH}$ distance $<1.3 \AA$, marked by the vertical dashed line in Fig 13). The hole jumps from the $\pi$ orbital of Pm to a p orbital of water for the first time at about 5 fs and continues to oscillate between Pm and water before it finally settles on water at about $20 \mathrm{fs}$. The $\mathrm{S}_{1}-\mathrm{S}_{0}$ energy gap decreases rapidly around $6 \mathrm{fs}$ and then more slowly until a $\mathrm{S}_{1}-\mathrm{S}_{0}$ degeneracy is reached at $34 \mathrm{fs}$, where the trajectory is stopped. The images at the bottom of Fig. 13 are three snapshots of the hole orbital, illustrating the hole transfer from Pm to the water cluster. 
a)

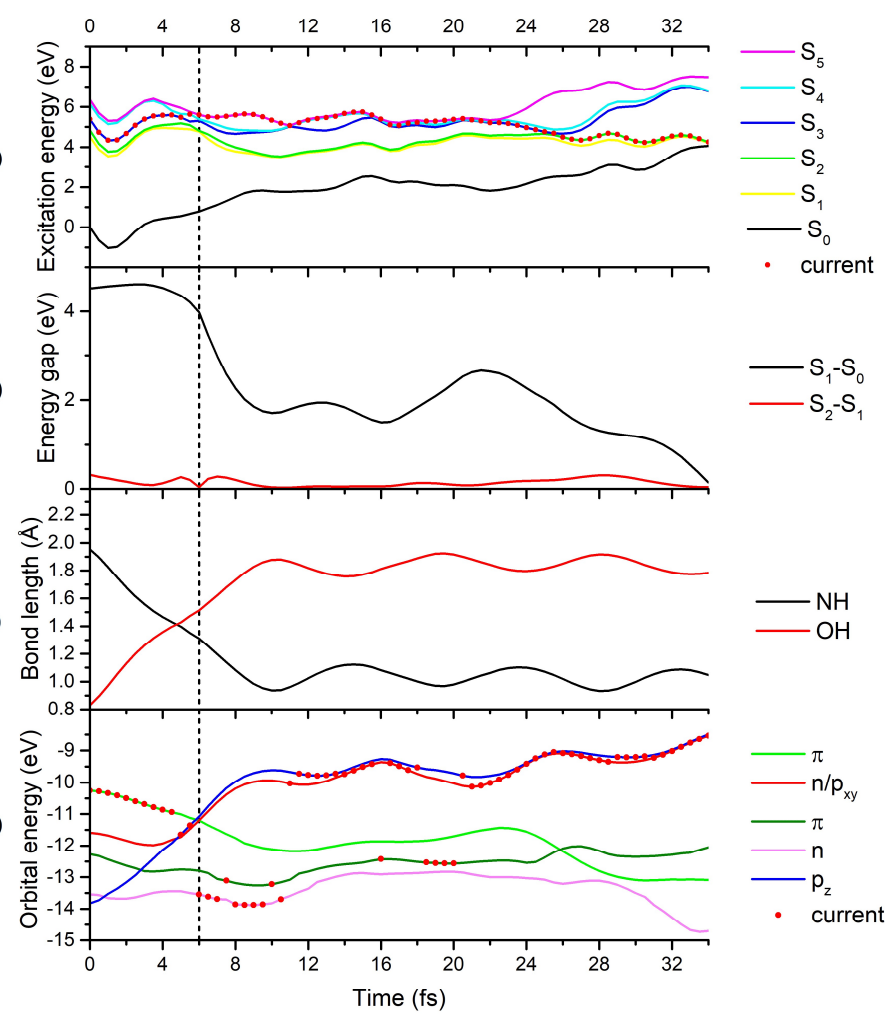

e)
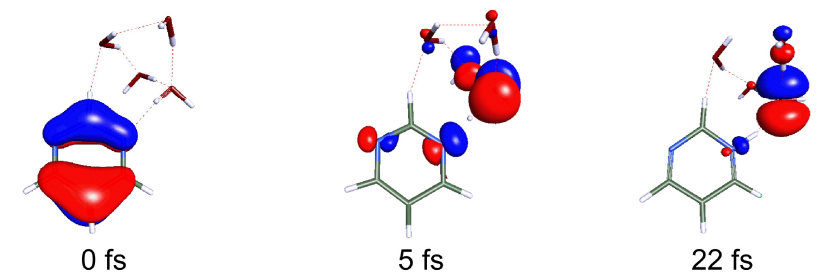

Figure 13. Time evolution of characteristic features of a representative trajectory (from the ensemble of Fig. 11) undergoing proton transfer before deactivation to the electronic ground state. From top to bottom: (a) energies of excited states and ground state; the dots mark the currently populated electronic state. (b) $S_{1}-S_{0}$ and $S_{2}-S_{1}$ energy gaps. (c) distances of the active $H$-atom from the donor $(O-H)$ and acceptor (N-H) atoms. (d) time evolution of orbital energies; the dots mark the current electronic hole. (e) hole orbital at selected times. The vertical dashed line in $(a)$-(d) marks the moment $\left(t=6 f_{s}\right)$ when $R_{N H}$ drops below 1.3 A.

\section{Discussion and Conclusions}

It has been shown in this work that excitation of the Pm molecule in water clusters to the $\pi \pi^{*}$ excited singlet state with $240 \mathrm{~nm}$ light can result in an $\mathrm{H}$-atom transfer reaction from a hydrogen-bonded water molecule to the Pm molecule. The reaction is demonstrated experimentally by the detection of the $\mathrm{PmH} \cdot$ radical via its ionization product, the $\mathrm{PmH}^{+}$ion, in a TOF mass spectrometer. The simultaneously 
generated $\mathrm{OH}^{\bullet}$ radical could not be detected in the present experimental setup. These results confirm that photoexcited Pm, like photoexcited $\mathrm{Py},{ }^{10}$ can oxidize water by a $\mathrm{H}$-atom transfer reaction in a cold aqueous environment. In addition, the electronic spectrum of the $\mathrm{PmH} \cdot$ radical has been characterized for the first time in the range $380 \mathrm{~nm}-330 \mathrm{~nm}$. This data should be useful for future studies of photoinduced radical generation in Pm-solvent clusters.

The experiments, performed with ns pulsed lasers, did not deliver information on the time scale of the $\mathrm{H}$-atom transfer reaction in the clusters, nor did they provide information on the quantum yield of the water oxidation reaction. To obtain deeper insight into the reaction dynamics, we performed firstprinciples numerical reaction dynamics simulations, using a quasi-classical trajectory SH algorithm in combination with ab initio $\mathrm{ADC}(2)$ electronic-structure calculations. The simulations were performed for two selected clusters, $\mathrm{Pm}-\mathrm{H}_{2} \mathrm{O}$ and $\mathrm{Pm}-\left(\mathrm{H}_{2} \mathrm{O}\right)_{4}$, to gather some information on the cluster-size dependence of the reactions. We were able to cover $500 \mathrm{fs}$ of ab initio simulation time. The trajectorybased simulations reveal the characteristic features of the competition between ultrafast non-reactive radiationless deactivation within the Pm chromophore and the excited-state PCET reaction with water.

The majority of the initially prepared population of the $S_{3}\left(\pi \pi^{*}\right)$ state of Pm was found to decay via the intermediate $\mathrm{S}_{2}\left(n \pi^{*}\right)$ state to the $\mathrm{S}_{1}\left(\mathrm{n} \pi^{*}\right)$ state within about 100 fs. In the Pm- $\left(\mathrm{H}_{2} \mathrm{O}\right)_{4}$ complex, Hatom transfer from the hydrogen-bonded water molecule to $\mathrm{Pm}$ is found to take place within $100 \mathrm{fs}$ in competition with the radiationless relaxation to the $S_{1}$ state, generating ground-state biradicals with a probability of a few percent. This ultrafast PCET reaction is absent in the $\mathrm{Pm}-\mathrm{H}_{2} \mathrm{O}$ complex. On longer (picosecond) timescales, the population of the $S_{1}\left(n \pi^{*}\right)$ state decays by internal conversion to the $S_{0}$ state. This radiationless decay in Pm is moderately enhanced by the water environment. For the $\mathrm{Pm}-\left(\mathrm{H}_{2} \mathrm{O}\right)_{4}$ cluster, $13 \%$ of the electronic population is found in the $\mathrm{S}_{0}$ state at $500 \mathrm{fs}$. On longer time scales (not covered by the present simulations), PCET yielding pyrimidinyl and hydroxyl radicals can occur from the relaxed population in the $\mathrm{S}_{1}$ state by $\mathrm{H}$-atom tunneling through the $\mathrm{H}$-atom transfer barrier on the $\mathrm{S}_{1}$ PE surface, see Fig 9. 
The analysis of individual trajectories reveals that the PCET reactivity is driven by an interplay of hydrogen-bond dynamics in the initially prepared $S_{3}$ state and electron-transfer dynamics. Upon shortening of the $\mathrm{NH}$ bond distance (or extension of the $\mathrm{OH}$ bond distance) in the $\mathrm{Pm}-\mathrm{H}_{2} \mathrm{O}$ hydrogen bond, the hole in the highest $\pi$ orbital (for the $\pi \pi^{*}$ excited state) or $n$ orbital (for $n \pi^{*}$ excited states) of Pm jumps to the O-atom of the water molecule. This hole transfer is followed by the transfer of the proton from the positively charged water molecule to the negatively charged Pm molecule, resulting in the irreversible formation of the $\mathrm{PmH} \cdot\left(\mathrm{H}_{2} \mathrm{O}\right)_{\mathrm{n}-1} \mathrm{OH} \cdot$ radical pair.

It is interesting to consider the Pm-water system in the context of other hydrogen-bonded clusters of N-heterocycles. The photophysical and photochemical dynamics of $\mathrm{Py}-\mathrm{H}_{2} \mathrm{O}$ and $\mathrm{Py}-\left(\mathrm{H}_{2} \mathrm{O}\right)_{4}$ clusters has been theoretically explored earlier with the same methodology and comparable statistics, ${ }^{54}$ which allows a qualitative comparison of the reaction mechanisms in $\mathrm{Py}-\left(\mathrm{H}_{2} \mathrm{O}\right)_{n}$ and $\mathrm{Pm}-\left(\mathrm{H}_{2} \mathrm{O}\right)_{n}$ clusters. Overall, the reaction dynamics of these clusters is very similar. The yield of the PCET reaction is strongly reduced in the cluster with a single water molecule compared to larger clusters. This is likely due to the lack of sufficient dynamical degrees of freedom which can accept the excess energy liberated by the H-atom transfer reaction. In the Py- $\left(\mathrm{H}_{2} \mathrm{O}\right)_{4}$ and $\mathrm{Pm}-\left(\mathrm{H}_{2} \mathrm{O}\right)_{4}$ clusters, the yield of radical pairs is around a few percent and the $\mathrm{H}$-atom transfer reaction occurs during the fast initial radiationless decay of the bright ${ }^{1} \pi \pi^{*}$ state. The vast majority of trajectories (about $90 \%$ ) relax to a local minimum of the $\mathrm{S}_{1}\left(\mathrm{n} \pi^{*}\right) \mathrm{PE}$ surface. The ensuing non-reactive internal conversion in the chromophores occurs on picosecond timescales and is moderately enhanced by the water environment.

The rather fast excited-state deactivation of the Py and Pm chromophores is an undesirable competing process for the photoinduced water oxidation with these chromophores and is responsible for the low overall yield of biradicals. In this respect, the heptazine chromophore stands out by exhibiting a truly long-lived $(\approx 300 \mathrm{~ns}$ ) first excited singlet state in which the energy of the absorbed photon can be stored. While Py and Pm are non-fluorescent, a fluorescence quantum yield of $\approx 70 \%$ was measured for the $\mathrm{S}_{1}$ state of TAHz in toluene. ${ }^{9}$ Investigations of the water oxidation reaction in clusters of $\mathrm{Hz}$ or $\mathrm{Hz}$ derivatives with water in a molecular beam would therefore be of great interest. 


\section{Supporting Information}

Additional computational data (Figs SI.1, SI.2). Additional experimental data (Figs SI.3 - SI.5).

\section{Notes}

The authors declare no competing financial interests.

\section{Acknowledgments}

This work has been conducted within the International Associated Laboratory LEMIR (CNRS/CONICET) and with the support of the ANR Research Grant ANR17CE05000502-Wsplit. The work at the Technical University of Munich was supported by the Deutsche Forschungsgemeinschaft (DFG) by a research grant and through the Munich Centre for Advanced Photonics (MAP).

\section{References}

1. X. Wang, K. Maeda, A. Thomas, K. Takanabe, G. Xin, J. M. Carlsson, K. Domen and M. Antonietti, Nat. Mater., 2009, 8, 76-80.

2. W.-J. Ong, L.-L. Tan, Y. H. Ng, S.-T. Yong and S.-P. Chai, Chem. Rev., 2016, 116, 7159-7329.

3. J. Wen, J. Xie, X. Chen and X. Li, Appl. Surf. Sci., 2017, 391, 72-123.

4. G. Liao, Y. Gong, L. Zhang, H. Gao, G.-J. Yang and B. Fang, Energy Environ. Sci., 2019, 12, 20802147.

5. T. Banerjee, K. Gottschling, G. Savaski, C. Ochsenfeld and B. V. Lotsch, ACS Energy Lett., 2018, 3, 400-409.

6. Y. Wang, X. Wang and M. Antonietti, Angew. Chem., Int. Ed., 2012, 51, 68-89.

7. Y. Wang, A. Vogel, M. Sachs, R. S. Sprick, L. Wilbraham, S. J. A. Moniz, R. Godin, M. A. Zwijnenburg, J. R. Durrant, A. I. Cooper and J. Tang, Nature Energy, 2019, 4, 746-760.

8. W. Domcke, J. Ehrmaier and A. L. Sobolewski, ChemPhotoChem, 2019, 3, 10-23.

9. E. J. Rabe, K. L. Corp, A. L. Sobolewski, W. Domcke and C. W. Schlenker, J. Phys. Chem. Lett., 2018, 9, 6257-6261.

10. N. Esteves-López, S. Coussan, C. Dedonder-Lardeux and C. Jouvet, Phys. Chem. Chem. Phys., 2016, 18, 25637-25644.

11. J. R. Reimers and Z.-L. Cai, Phys. Chem. Chem. Phys., 2012, 14, 8791-8802.

12. X. Liu, A. L. Sobolewski, R. Borrelli and W. Domcke, Phys. Chem. Chem. Phys., 2013, 15, 59575966.

13. X. Liu, A. L. Sobolewski and W. Domcke, J. Phys. Chem. A, 2014, 118, 7788-7795.

14. T. Droz, R. Knochenmuss and S. Leutwyler, J. Chem. Phys., 1990, 93, 4520-4532.

15. A. Müller, F. Talbot and S. Leutwyler, J. Am. Chem. Soc., 2002, 124, 14486-14494.

16. K. Sakota, C. Okabe, N. Nishi and H. Sekiya, J. Phys. Chem. A, 2005, 109, 5245-5247.

17. G. A. Pino, I. Alata, C. Dedonder, C. Jouvet, K. Sakota and H. Sekiya, Phys. Chem. Chem. Phys., 2011, 13, 6325-6331. 
18. G. Pino, C. Dedonder-Lardeux, G. Grégoire, C. Jouvet, S. Martrenchard and D. Solgadi, J. Chem. Phys., 1999, 111, 10747-10749.

19. S.-I. Ishiuchi, M. Sakai, K. Daigoku, T. Ueda, T. Yamanaka, K. Hashimoto and M. Fujii, Chem. Phys. Lett., 2001, 347, 87-92.

20. C. Dedonder-Lardeux, D. Grosswasser, C. Jouvet and S. Martrenchard, PhysChemComm, 2001, 4, 21-23.

21. V. Stert, L. Hesse, H. Lippert, C. Schulz and W. Radloff, J. Phys. Chem. A, 2002, 106, 5051-5053.

22. O. David, C. Dedonder-Lardeux and C. Jouvet, Int. Rev. Phys. Chem., 2002, 21, 499-523.

23. A. Carrera, I. Nielsen, P. Carcabal, C. Dedonder, M. Broquier, C. Jouvet, W. Domcke and A. L. Sobolewski, J. Chem. Phys., 2009, 130, 024302.

24. G. Pino, A. Oldani, E. Marceca, M. Fujii, S.-I. Ishiuchi, M. Miyazaki, M. Broquier, C. Dedonder and C. Jouvet, J. Chem. Phys., 2010, 133, 124313.

25. A. Courty, M. Mons, I. Dimicoli, F. Piuzzi, M.-P. Gaigeot, V. Brenner, P. de Pujo and P. Millié, J. Phys. Chem. A, 1998, 102, 6590-6600.

26. H. M. Kim, K. Y. Han, J. Park, G.-S. Kim and S. K. Kim, J. Chem. Phys., 2008, 128, 041104.

27. K. Tanabe, M. Miyazaki, M. Schmies, A. Patzer, M. Schütz, H. Sekiya, M. Sakai, O. Dopfer and M. Fujii, Angew. Chem., Int. Ed., 2012, 51, 6604-6607.

28. C. Jouvet and B. Soep, Chem. Phys. Lett., 1983, 96, 426-428.

29. W. Breckenridge, C. Jouvet and B. Soep, J. Chem. Phys., 1986, 84, 1443-1450.

30. M. Dantus, M. J. Rosker and A. H. Zewail, J. Chem. Phys., 1987, 87, 2395-2397.

31. A. Zehnacker and M. A. Suhm, Angew. Chem., Int. Ed., 2008, 47, 6970-6992.

32. C. Dedonder - Lardeux, C. Jouvet, M. Richard - Viard and D. Solgadi, J. Chem. Phys., 1990, 92, 2828-2836.

33. I. Alata, R. Omidyan, M. Broquier, C. Dedonder and C. Jouvet, Chem. Phys., 2012, 399, 224-231.

34. C. Møller and M. S. Plesset, Phys. Rev., 1934, 46, 618-622.

35. J. Schirmer, Phys. Rev. A, 1982, 26, 2395-2416.

36. A. B. Trofimov and J. Schirmer, J. Phys. B: At., Mol. Opt. Phys., 1995, 28, 2299-2324.

37. C. Hättig, in Adv. Quantum Chem., ed. H. J. Å. Jensen, Academic Press2005, vol. 50, pp. 37-60.

38. J. Ehrmaier, M. J. Janicki, A. L. Sobolewski and W. Domcke, Phys. Chem. Chem. Phys., 2018, 20, 14420-14430.

39. T. H. Dunning Jr., J. Chem. Phys., 1989, 90, 1007-1023.

40. TURBOMOLE (V7.2), a development of University of Karlsruhe and Forschungszentrum Karlsruhe GmbH, 1989-2007, TURBOMOLE GmbH, since 2007.

41. C. Hättig and F. Weigend, J. Chem. Phys., 2000, 113, 5154-5161.

42. J. P. Bergsma, P. H. Berens, K. R. Wilson, D. R. Fredkin and E. J. Heller, J. Phys. Chem., 1984, 88, 612-619.

43. M. Barbatti, Wiley Interdiscip. Rev.: Comput. Mol. Sci., 2011, 1, 620-633.

44. A. K. Belyaev and O. V. Lebedev, Phys. Rev. A, 2011, 84, 014701.

45. A. K. Belyaev, W. Domcke, C. Lasser and G. Trigila, Journal of Chemical Physics, 2015, 142, 104307.

46. W. Xie and W. Domcke, J. Chem. Phys., 2017, 147, 184114.

47. W. Xie, M. Sapunar, N. Doslic, M. Sala and W. Domcke, J. Chem. Phys., 2019, 150, 154119.

48. J. C. Tully, J. Chem. Phys., 1990, 93, 1061-1071.

49. L. Yu, C. Xu, Y. Lei, C. Zhu and Z. Wen, Phys. Chem. Chem. Phys., 2014, 16, 25883-25895.

50. K. Hanasaki, M. Kanno, T. A. Niehaus and H. Kono, J. Chem. Phys., 2018, 149, 244117.

51. X. Pang, J. Ehrmaier, X. Wu, C. Jiang, W. Xie, A. L. Sobolewski and W. Domcke, Chem. Phys., 2018, 515, 550-556.

52. I. Alata, J. Bert, M. Broquier, C. Dedonder, G. Feraud, G. Gregoire, S. Soorkia, E. Marcea and C. Jouvet, J. Phys. Chem. A, 2013, 117, 4420-4427.

53. M. H. V. Huynh and J. J. Meyer, Chem. Rev., 2007, 107, 5004-5064.

54. X. Pang, C. Jiang, W. Xie and W. Domcke, Phys. Chem. Chem. Phys., 2019, 21, 14073-14079. 


\section{TOC graphics}

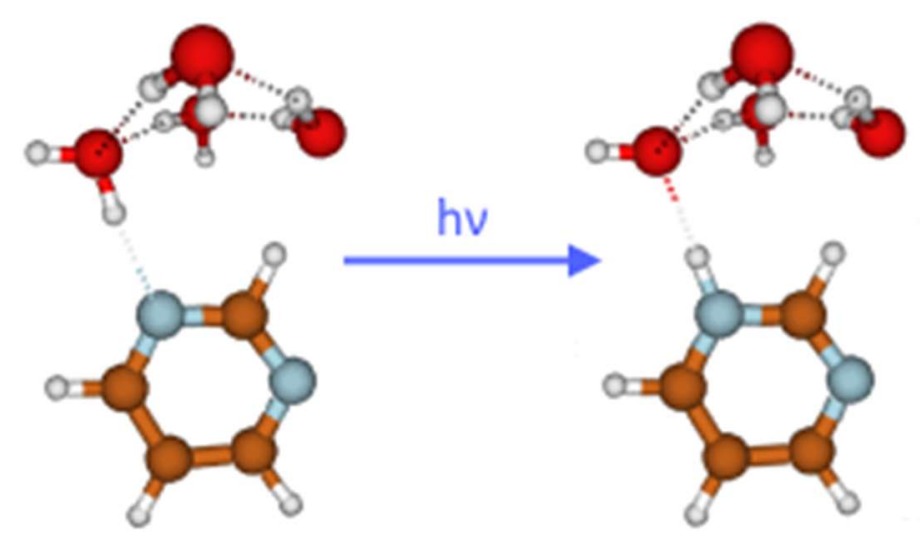

The photochemical oxidation of water molecules in pyrimidine-water complexes has been explored in a combined experimental and theoretical study. 